Título artículo / Títol article: Metabolic and Regulatory Responses in Citrus rootstock in Response to Adverse Environmental Conditions

Autores / Autors

Argamasilla, Rosa ; Gómez Cadenas, Aurelio ; Arbona Mengual, Vicent

Revista:

Journal of Plant Growth Regulation June 2014, Volume 33

Versión / Versió:

Postprint de l'autor

Cita bibliográfica / Cita bibliogràfica (ISO 690):
ARGAMASILLA, Rosa; GÓMEZ-CADENAS, Aurelio; ARBONA, Vicent. Metabolic and regulatory responses in citrus rootstocks in response to adverse environmental conditions. Journal of Plant Growth Regulation, 2014, 33.2: 169-180.

url Repositori UJI: http://hdl.handle.net/10234/127405 


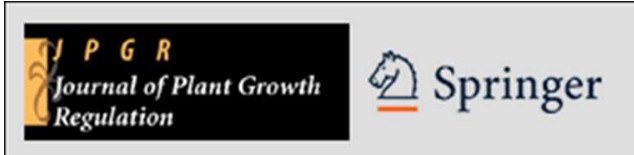

\section{Metabolic and regulatory responses in citrus rootstocks in response to adverse environmental conditions}

\begin{tabular}{|r|l|}
\hline Journal: & Journal of Plant Growth Regulation \\
\hline Manuscript ID: & JPGR-13-0044.R1 \\
\hline Manuscript Type: & Original Manuscripts \\
\hline Date Submitted by the Author: & n/a \\
\hline Complete List of Authors: & $\begin{array}{l}\text { Argamasilla, Rosa; Universitat Jaume I (UJI), Dept. Ciències Agràries i del } \\
\text { Medi Natural } \\
\text { Gómez-Cadenas, Aurelio; Universitat Jaume I (UJI), Dept. Ciències } \\
\text { Agràries i del Medi Natural } \\
\text { Arbona, Vicent; Universitat Jaume I (UJI), Dept. Ciències Agràries i del } \\
\text { Medi Natural }\end{array}$ \\
\hline Keywords: & $\begin{array}{l}\text { abiotic stress, drought, metabolomics, plant hormones, phenylpropanoids, } \\
\text { soil flooding }\end{array}$ \\
\hline &
\end{tabular}


Title: Metabolic and regulatory responses in citrus rootstocks in response to adverse environmental conditions

Running title: Metabolomics of abiotic stress in citrus

Authors: Rosa Argamasilla, Aurelio Gómez-Cadenas, Vicent Arbona*

Affiliation: Ecofisiologia i Biotecnologia. Departament de Ciències Agràries i del Medi Natural. Universitat Jaume I. Castelló de laPlana, Spain.

\section{Corresponding Author:}

Vicent Arbona

Dept. Ciències Agràries i del Medi Natural

Universitat Jaume I.

E-12071 Castelló de la Plana

Spain

e-mail: vicente.arbona@camn.uji.es

Ph. +34 964728101

Fax. +34964728216 


\section{Abstract}

In response to adverse environmental conditions, plants modify their metabolism in order to adapt to the new conditions. To differentiate common responses to abiotic stress from specific adaptation to a certain stress condition, two citrus rootstocks (Carrizo citrange and Cleopatra mandarin) with a different ability to tolerate stress were subjected to soil flooding and drought, two water stress conditions. In response to these conditions, both genotypes showed altered root proline and phenylpropanoid levels, especially cinnamic acid that was a common feature to Carrizo and Cleopatra. This was correlated with alterations in the levels of phenylpropanoid derivatives likely involved in lignin biosynthesis. In the regulatory part, levels of both stress hormones ABA and JA decreased in response to soil flooding irrespective of the genotype relative flooding tolerance but, on the contrary, concentration of both metabolites increased in response to drought, showing JA a transient accumulation after a few days and ABA a progressive pattern of increase. These responses are probably associated to different regulatory processes under soil flooding and drought. In addition, alterations in IAA levels in citrus roots seemed to be associated to particular stress tolerance. Moreover, both genotypes exhibited a low degree of overlapping in the metabolites induced under similar stress conditions, indicating a specific mechanism to cope with stress in plant species. Results also indicated a different metabolic basal status in both genotypes that could contribute to stress tolerance.

Keywords: abiotic stress, drought, metabolomics, plant hormones, phenylpropanoids, soil flooding, 


\section{Introduction}

Environmental variables such as temperature, water availability, irradiance or soil osmolality affect plants in different ways depending on their ability to tolerate a specific adverse situation (Des Marais and Juenger 2010, Qin and others 2011). The most damaging situation is probably water shortage that dramatically affects plant performance and, ultimately, survival. This water deprivation is mainly due to a limitation in the availability of capillary water or liquid water trapped between the soil particles which can be efficiently absorbed by plant roots. Plants respond to this situation by accumulating compatible solutes or soil salts thus decreasing their water potential and closing stomata to avoid dehydration (Munns 2011). A paradigmatic situation is salt stress that has a double component: a first phase of osmotic stress and a second phase of ionic stress that occurs after over-accumulation of toxic ions, such as $\mathrm{Na}^{+}$and $\mathrm{Cl}^{-}$, in photosynthetic organs (Munns 2011).

In citrus, the accumulation of $\mathrm{Cl}^{-}$in leaves induces down-regulation of the photosynthetic system and reduction in gas exchange parameters, ultimately leading to the overproduction of reactive oxygen species and oxidative stress (Arbona and others 2003, López-Climent and others 2008). As well as in salt stress, the intensity of the response to water deprivation is related to the ability of the plant to regulate water relations (Moya and others 2003). Those genotypes with a lower transpiration rate and a higher ability to rapidly close stomata (for example, Cleopatra mandarin) have improved performance under drought conditions (López-Climent and others 2008). Citrus responses to abiotic stress also include accumulation of jasmonic acid (JA) and abscisic acid (ABA) in roots and leaves (de Ollas and others 2012, Gómez-Cadenas and 
others 1996). In addition, there is an accumulation of 1-aminocyclopropane-1carboxylic acid in water-stressed roots that can be eventually transported to the aerial part and oxidized to ethylene triggering leaf and organ drop (Gómez-Cadenas and others 1996).

On the contrary, when subjected to other situations that induce water shortage such as soil flooding, plants develop different strategies to cope with stress (Arbona and others 2008, Arbona and Gómez-Cadenas 2008, Arbona and others 2009b). In citrus, tolerance to soil flooding seems to be associated to higher transpiration rates and root hydraulic conductivity. In a previous work, Arbona and others (2009b) found that under continuous soil flooding Carrizo citrange plants did not show any alteration in gas exchange or chlorophyll fluorescence parameters for thirty days whereas both parameters rapidly decreased in plants of the sensitive genotype Cleopatra mandarin that also exhibited leaf mid-vein yellowing and curling symptoms. Soil flooding tolerance was also correlated to the ability to delay JA and ABA accumulation in leaves. However, no variations in the hormonal profile that could be linked to tolerance were found in roots since both JA and ABA levels importantly decreased right after stress imposition (Arbona and Gómez-Cadenas 2008).

\footnotetext{
All these results, taken together, indicate that specific hormonal signalling profiles might have evolved associated to particular stress situations. Nevertheless, stressed plants exhibit similar physiological responses. Then, the question whether different signalling events regulate similar biochemical responses or not, seems of particular relevance in this context.
} 
Based on our knowledge, citrus genotypes with varying ability to tolerate different water shortage situations show similar physiological responses (stomatal closure, downregulation of photosynthesis and production of reactive oxygen species) when subjected to abiotic stress situations (Arbona and others 2003, 2008). However, under identical stress conditions, model plants alter their metabolism in different ways, causing diverse secondary metabolite profiles (Arbona and others 2010). This different response could be associated to a particular basal secondary metabolite composition but also to a different regulation of the metabolism. In a previous publication, Arbona and others (2010) found that even close-related plant genotypes showed very little overlapping in the metabolites altered by a specific stress condition.

Phenolic derivatives constitute the most diverse array of secondary metabolites found in plants. In particular, phenylpropanoids (cinnamic acid, coumaric acid, caffeic acid and ferulic acid) are synthesized from phenylanaline via phenylalanine ammonia lyase (PAL), a enzyme that catalyzes its deamination rendering cinnamic acid, the first precursor of flavonoid and lignin biosynthesis. The increase in PAL activity and phenylpropanoid content under different adverse environmental conditions has been reported (Cabane and others 2012, Moura and others 2010, Vincent and others 2005). Phenylpropanoids are precursors of lignins, which constitute an important stress defense mechanism, especially at the root level where these compounds are involved in cell wall composition and stiffness (Cabane and others 2012, Vincent and others 2005). Besides the structural function of phenylpropanoids, a role as antioxidants has been proposed (Moura and others 2010). As a response to soil flooding, citrus increase their antioxidant capacity in terms of enzyme activity and soluble antioxidants (Arbona and others 2008). Along with this response, flavonoid levels in tolerant genotypes were less 
affected than in sensitive ones, suggesting that flavonoids might be also part of their tolerance mechanism (Djoukeng and others 2008).

Other secondary metabolites known to have a functional role in response to abiotic stresses are carotenoids and xantophylls. These compounds are lipophilic compounds synthesized in plants from isopentenyl pyrophosphate (IPP) via the plastidial methyl erythritol phosphate (MEP) pathway. Xantophylls are synthesized from $\beta$-carotene via its conversion to zeaxanthin and sequentially to violaxanthin by epoxidation. Finally, an arrangement in one epoxy ring of violaxanthin to form an allenic bond forms neoxanthin, the precursor of ABA in plants. In this sense, overexpression of carotenoid biosynthetic genes in transgenic tobacco plants improved osmotic and salt stress tolerance by channelling carotenoid flux to ABA biosynthesis leading to increased levels of this phytohormone (Cidade and others 2012).

To investigate hormonal and secondary metabolite responses and their relationship with abiotic stress tolerance, two stress conditions: progressive drought and soil flooding were assayed in two citrus genotypes used as rootstocks in modern citriculture: Carrizo citrange and Cleopatra mandarin. These rootstocks were chosen because of their different tolerance to the stress conditions assayed. The study focuses on roots as the first organ sensing the stress derived from soil water perturbation. Proline accumulation, hormonal and secondary metabolite profiles were analyzed in the two rootstock species under the two stress conditions mentioned above.

\section{Materials and methods}

Plant material, treatments and sample collection 
Four-month-old horticulturally true-to-type seedlings of Cleopatra mandarin (Citrus reshni Hort. ex Tan.) and Carrizo citrange (Citrus sinensis L. Osb. $\times$ Poncirus trifoliata L. Raf.) were used in soil flooding and drought experiments. Plants were purchased from a commercial nursery and immediately transplanted to 2-L plastic pots with different substrates depending on the kind of experiments (see below). Before the onset of the experiments, all plants were watered three times a week as described in (Arbona and others 2006) and allowed to acclimate for 2 months. During plant acclimation and experiments, plants were kept in a greenhouse under the following conditions: $26 \pm 4.0$ ${ }^{\circ} \mathrm{C}$ day temperature, $18 \pm 3.0{ }^{\circ} \mathrm{C}$ night temperature, relative humidity between 70 and $90 \%$, and a 16-h photoperiod.

Flooding stress

To carry out flooding experiments a mixture of peat moss:perlite:vermiculite in an 8:1:1 ratio was used as a substrate. At the end of the acclimation period, two groups of 12 plants each were selected based on the uniformity in appearance and state of development: one was set as control and watered three times a week as described in in Arbona and others (2006) and the other group was subjected to soil waterlogging. To impose stress, pots were placed in opaque plastic bags and then into pots of higher capacity (4 L) and filled with tap water until complete saturation of the soil field capacity, adding more water when needed. Root samples of three plants per treatment group were collected after 1, 3, 6 and 8 days of treatment. Young roots were selected and immediately frozen in liquid nitrogen. The samples were stored at $-80{ }^{\circ} \mathrm{C}$ until analyses.

Drought stress 
Before experiments, a total of 30 citrus seedlings were transplanted to plastic pots using perlite as a substrate that allows a tight control of the water content due to its low moisture-retaining capacity. Half of the plants were used as controls and watered three times a week as described in Arbona et al. (2006) and the other was subjected to drought by simply stop watering. The treatment lasted for 14 days when leaf symptoms of dehydration were apparent. Throughout this period, young root samples from three plants per treatment were collected at days 3, 5, 7, 12 and 14, frozen immediately in liquid nitrogen and stored at $-80{ }^{\circ} \mathrm{C}$ for further analyses.

\section{Proline analysis}

Ground frozen leaf tissue $(0.05 \mathrm{~g})$ was extracted in $5 \mathrm{ml}$ of $3 \%$ sulfosalicylic acid (Panreac, Barcelona, Spain) using a homogenizer (Ultra-Turrax, IKA-Werke, Staufen, Germany), at maximum speed. After centrifugation at $4,000 \times g$ for $35 \mathrm{~min}$ at $4{ }^{\circ} \mathrm{C}$, proline was determined as described by Bates and others (1973). Briefly, $1 \mathrm{ml}$ of the supernatant was combined with $2 \mathrm{ml}$ of a mixture of glacial acetic acid and ninhydrin reagent (Panreac) in a 1:1 (v:v) ratio. The reaction mixture was incubated in a water bath at $100^{\circ} \mathrm{C}$ for $1 \mathrm{~h}$ and then partitioned against $2 \mathrm{ml}$ of toluene. Absorbance was read in the organic layer at $520 \mathrm{~nm}$. A standard curve was performed with standard proline (Sigma-Aldrich, Madrid, Spain).

\section{Phytohormone analyses}

Plant hormone and different phenylpropanoids (cinnamic, caffeic, coumaric and ferulic acids) were extracted and analyzed essentially as described in Durgbanshi and others (2005) with slight modifications. Briefly, $0.5 \mathrm{~g}$ of ground frozen plant material was extracted in $5 \mathrm{ml}$ of distilled water after spiking with $100 \mathrm{ng}$ of $d_{6}$-ABA, prepared as in Gómez-Cadenas and others (2002); dihydrojasmonic acid (100 ng), synthesized in the 
laboratory by catalyzed hydrogenation (Kristl and others 2005), and $\left[{ }^{2} \mathrm{H}_{2}\right]$-IAA (10 ng, Sigma-Aldrich) . After centrifugation at $4,000 \times g$ at $4^{\circ} \mathrm{C}$, supernatants were recovered and $\mathrm{pH}$ adjusted to 3.0 with $30 \%$ acetic acid. The acidified water extract was partitioned twice against $3 \mathrm{ml}$ of diethyl ether. The organic upper layer was recovered and evaporated under vacuum in a centrifuge concentrator (Speed Vac, Jouan, Saint Herblain Cedex, France). The dry residue was then suspended in a 10\% $\mathrm{MeOH}$ solution by gentle sonication. The resulting solution was filtered through regenerated cellulose $0.22 \mu \mathrm{m}$ membrane syringe filters (Albet S.A., Barcelona, Spain) and directly injected into the HPLC system (Waters Alliance 2695, Waters Corp., Milford, MA, USA). Separations were carried out on a C18 column (Kromasil $1005 \mu \mathrm{m}$ particle size, $100 \times 2.1 \mathrm{~mm}$, Scharlab, Barcelona, Spain) using a linear gradient of $\mathrm{MeOH}$ and $\mathrm{H}_{2} \mathrm{O}$ supplemented with $0.01 \%$ acetic acid at a flow rate of $300 \mu 1 \mathrm{~min}^{-1}$. Hormone and phenylpropanoid fractions were detected with a Quattro LC triple quadrupole mass spectrometer (Micromass, Manchester UK) connected online to the output of the column through an orthogonal Z-spray electrospray ion source. Quantitation of plant hormones and phenylpropanoids was achieved by external calibration with standards of known amount.

\section{Metabolite profiling analyses}

\section{Extraction and LC conditions}

Samples from roots of Cleopatra and Carrizo $(0.1 \mathrm{~g})$ were double extracted in $200 \mu \mathrm{l}$ of a $80 \%$ aqueous $\mathrm{MeOH}$ solution by gentle ultrasonication, centrifuged at $10,000 \times g$ at $4^{\circ} \mathrm{C}$ for $10 \mathrm{~min}$ and filtered through PTFE membrane filters $(0.45 \mu \mathrm{m}$ pore size $)$. Filtered extracts were subjected to RP-HPLC on a C18 column ( $5 \mu \mathrm{m}$ particle size, $100 \times 2.1 \mathrm{~mm}$, XTerra $^{\mathrm{TM}}$, Waters) with a Waters Alliance 2965 HPLC system using a 
linear gradient of ultrapure $\mathrm{H}_{2} \mathrm{O}$ (A) and HPLC-grade acetonitrile (B) both supplemented with formic acid to a $0.1 \%(\mathrm{v} / \mathrm{v})$ concentration at a flow rate of $300 \mu 1$ $\min ^{-1}$. The gradient used was: (0-4 min) 95:5 (A:B), (4.01-55 min) 5-95 (B), (55.01-60 $\min$ ) 95-5 (B) and (60.01-65 min) 95:5 (A:B). Before extraction, samples were spiked with known amounts of standard compounds: kinetin, biochanin A, rutin, $o$-anisic acid, ferulic acid and $\mathrm{N}$-(3-indolylacetyl)-L-phenylalanine, all purchased from SigmaAldrich.

\section{QTOF-MS conditions}

Column eluates were introduced into the mass spectrometer, a QTOF I from Micromass Ltd. (Manchester, UK), through an orthogonal electrospray source (ESI) operated in positive mode. Nitrogen was employed as nebulization as well as desolvation gas and working flows were set at 100 and 800 arbitrary units, respectively. Source block temperature was kept at $120^{\circ} \mathrm{C}$ and desolvation gas at $350{ }^{\circ} \mathrm{C}$. Capillary, cone and extractor voltages were set at $4 \mathrm{kV}, 25 \mathrm{eV}$ and $3 \mathrm{eV}$, respectively. Before analyses, QTOF mass spectrometer was calibrated by infusing a mixture of $\mathrm{NaOH}$ and $\mathrm{HCOOH}$ at a flow rate of $25 \mu 1 \mathrm{~min}^{-1}$. After calibration, the average error was less than $5 \mathrm{ppm}$. During acquisition, a 1 ppm solution of Leu-enkephalin $\left([\mathrm{M}+\mathrm{H}]^{+}=556.2771\right)$ was continuously post column infused as a lock mass reference. Data were acquired under continuous mode in the 50-900 amu range, scan duration was set at $1.0 \mathrm{~s}$ and inter-scan delay at $0.1 \mathrm{~s}$.

\section{Assessment of reproducibility}

This test was accomplished following the workflow described in Arbona and others (2010). Annotated chromatographic mass features covering the whole chromatographic run were selected as markers for subsequent linearity assessment. Selected candidates 
were integrated using MassLynx v. 4.1 throughout extraction and injection sample replicates and variations in retention time and area were collected as markers of stability of the chromatographic system (Supplementary data 1).

\section{Assessment of linearity}

Plant samples were extracted, diluted and analyzed as in Arbona and others (2010). Afterwards selected features were integrated with Masslynx v. 4.1 and area values represented using MS Excel (Supplementary data 2 and 3). The dilution representing the average point within the dynamic linear range was selected as the optimum dilution to analyze experiments.

\section{Analysis of samples}

Plant samples were extracted and analyzed as above using the adequate dilutions and spiking samples with known amounts of selected internal standards to assess recovery and stability of the system as indicated in Extraction and LC conditions section. XCMS analysis was carried out essentially as described before after centroidization of files (Arbona and others 2009a, Arbona and others 2010). Before statistical analyses, area values in datasets were appropriately normalized. To extract significantly altered mass signals in response to flooding and drought stress, analyses were performed with maSigPro algorithms as described in Arbona and others (2010). Reference standards for confirmation of annotated metabolites were purchased from Sigma-Aldrich when available.

\section{Data analysis}

For analyses, three independent biological replicates (plants) per treatment and date were analyzed. Every biological sample was analyzed in duplicate as technical 
replicates and the results within a given biological sample averaged. Statistical difference between stressed and control values was assessed by the student's t-test on each sampling date. For metabolomics analyses, significantly altered profiles were assessed using maSigPro algorithms as described above. In order to facilitate visualization of data and interpretation of results, these were expressed as $\log _{2}$ of the ratio of stress to control values.

\section{Results}

In Figure 1, the proline accumulation profile in roots of Cleopatra mandarin (a) and Carrizo citrange (b) plants subjected to soil flooding and progressive drought is shown. To facilitate interpretation, all results were expressed as $\log _{2}$ of stress/control ratio of each metabolite concentration. In the two genotypes and stress conditions, proline concentrations ranged between 5.1 and $57.6 \mu \mathrm{mol} \mathrm{g}{ }^{-1}$ fw (data not shown). In response to drought, proline levels increased showing very low accumulation ratios in both genotypes, even after 14 days of withholding water supply. In addition, proline levels in roots of Cleopatra showed a progressive accumulation upon drought that could not be clearly identified in Carrizo. In response to soil flooding the resulting picture was different: roots of Carrizo showed a stronger proline accumulation (a maximum 7.7-fold increase in Carrizo after 8 days of flooding versus only a 1.4-fold in Cleopatra after 6 days). At earlier time points only moderate increases could be observed (0.95 to 1.26fold on average) in roots of both genotypes.

Accumulation of cinnamic and coumaric acids from the phenylpropanoid pathway in citrus roots under abiotic stress is shown in Figure 2. Under the same soil flooding conditions, cinnamic acid accumulated in roots of both genotypes to similar extents. On 
the contrary, this metabolite showed a moderate and constant accumulation in Carrizo plants (equivalent to a 2 -fold increase) from 5 days of stress on in response to drought. However, in roots of Cleopatra plants subjected to the same conditions, cinnamic acid levels did not increase with respect to control plants and kept an erratic profile with an initial increase followed by a transient decrease after 5 days. After these initial variations, levels of the metabolite kept at control levels.

On the other side, coumaric acid levels increased in roots of both genotypes in response to soil flooding, however this increase was more consistent in Cleopatra at the end of the experimental period whereas in Carrizo it was more erratic only showing significant increases on the first and last sampling dates. In response to drought, coumaric acid levels decreased below controls in roots of both genotypes. Levels of the rest of phenylpropanoids (ferulic and caffeic acids) in roots of both genotypes did not exhibit any significant change in response to the stress conditions assayed (data not shown).

The $\log _{2}$ (stress/control) values of JA and ABA concentration in roots of citrus is presented in Figure 3. Both JA and ABA levels followed similar trends in the two citrus species studied when subjected to soil flooding, exhibiting significant and profound decreases (final levels were $5.0 \%$ and $6.3 \%$ of control values for $\mathrm{ABA}$ and JA, respectively in Carrizo). Only differences in the degree of reduction were observed when comparing hormone concentration profiles between both genotypes despite their different tolerance to this abiotic stress factor. Drought induced less dramatic changes in hormonal content compared to soil flooding. In previous works (De Ollas and others 2012), when subjected to drought, citrus roots exhibit a transient JA accumulation followed by a progressive ABA build up. In the present work, both Carrizo and Cleopatra showed JA and ABA accumulation patterns similar to those previously 
reported. Nevertheless, increases of both hormones in response to drought were more pronounced in drought-sensitive Carrizo than tolerant Cleopatra.

Changes in IAA levels in response to soil flooding and drought are shown in Figure 4. IAA levels accumulated always at the end of the experimental period. In Cleopatra roots, an important increase (about 8.0-fold in absolute values) occurred at 6 and $8 \mathrm{~d}$ of soil flooding stress. In Carrizo, this increase occurred only after 6 days of soil flooding. When subjected to drought stress, changes in IAA concentration profiles were very similar: starting with reductions below controls and ended with increases at the two last days of sampling.

\section{Metabolite profiling analyses}

Root samples of Carrizo citrange and Cleopatra mandarin under control conditions and subjected to drought and soil flooding were analyzed by means of LC/ESI-QTOF-MS. Each experiment was analyzed separately using treatment (control vs stressed) and time point as the two main factors to take into account. Significantly altered mass chromatographic features were grouped into four tendency clusters (Supplementary Data 4 and 5). To validate samples, internal standards added before extraction (see material and methods section) were integrated throughout samples and no significant differences between sample groups were detected (data not shown). Tentative annotations were achieved by searching the most plausible structures in Pubchem (http://pubchem.ncbi.nlm.nih.gov/), Chemspider (http://www.chemspider.com/) or Knapsack (http://www.knapsack.jp) databases.

\section{Soil flooding}

Only two out of four tendency clusters obtained in Carrizo plants subjected to soil flooding were considered biologically meaningful: cluster 1 in which 60 mass 
chromatographic features accounting for 9 putative metabolites showing an accumulating trend over time were grouped and cluster 4 that grouped only 34 mass chromatographic features accounting for 7 putative metabolites that were transiently accumulated after one day of stress but then returned to control values. Clusters 2 and 3 were discarded as biologically meaningful due to their odd behaviour that was attributed to biological variance not related to the stress imposition. After analyzing data from Cleopatra mandarin under the same stress conditions, the four clusters obtained were considered biologically meaningful: cluster 1 was equivalent to cluster 4 in Carrizo, showing 103 mass chromatographic features accounting for 8 metabolites transiently increased after 1 day of stress; cluster 4 with 55 chromatographic mass features, accounting for 13 putative metabolites, was equivalent to cluster 1 in Carrizo. In addition, cluster 2 grouped mass chromatographic features which levels decreased below controls over the entire stress period (64 chromatographic peaks and 12 putative metabolites) and cluster 3 contained mass chromatographic features which levels exhibited a transient increase after one day of stress but decreased below control levels afterwards (the most abundant cluster with 107 peaks accounting for a total of 12 potential metabolites). A total of 329 mass chromatographic features with differential accumulation respect to control plants were found in Cleopatra subjected to soil flooding (Supplementary Data 4). An overlapping test was performed by comparing the differentially expressed mass features in Carrizo and Cleopatra in response to soil flooding (Figure 5). Out of 94 and 329 differential mass chromatographic features in Carrizo and Cleopatra, respectively, only 15 were found to be common, accounting for 4 putative metabolites. Two of the mass chromatographic features that showed a similar behaviour in the two genotypes were annotated as 12-oxophytodienoic acid (OPDA, th $[\mathrm{M}+\mathrm{H}]^{+}$293.2116, exp $[\mathrm{M}+\mathrm{H}]^{+}$293.2170, $\Delta \mathrm{Da} 0.0054$, identified by comparison to a 
commercial standard) or a molecule carrying the same OPDA moiety (probably a conjugate, although its identity could not be confirmed). Figure 6 , shows OPDA levels below controls in both genotypes thus resembling the behaviour of its derivative JA (see Figure 3). On the contrary, the metabolite carrying the OPDA moiety presented an opposite behaviour increasing upon imposition of soil flooding stress in both genotypes. Another tentatively annotated metabolite was a putative ferulic acid derivative which base peak at $m / z 251.1329$ showed a clear fragment at $m / z 195.069\left({ }_{\mathrm{th}}[\mathrm{M}+\mathrm{H}]^{+} 195.0653\right.$, $\Delta \mathrm{Da} 0.0037$, the mass spectrum of this fragment was compared to that of authentic ferulic acid). The mass difference 56.06 was associated to the existence of four methyl units $\left(\mathrm{C}_{4} \mathrm{H}_{8} \Delta \mathrm{Da}\right.$ 0.0025). The extracted ion chromatograms of the 195.069 ion showed an increasing pattern in response to soil flooding, although in controls it was almost undetectable. In this case, maximum levels were higher in Cleopatra than in Carrizo (Figure 6).

Drought

In response to water stress, a total of 276 and 253 differential mass chromatographic features were found in Carrizo citrange and Cleopatra mandarin roots. As in response to soil flooding, little overlapping was observed, only four mass chromatographic features accounting for one putative metabolite (Figure 5). This metabolite was tentatively annotated as hydroxycinnamyl alcohol glucoside $\left({ }_{t h}[\mathrm{M}+\mathrm{H}]^{+} 313.1287 \exp [\mathrm{M}+\mathrm{H}]^{+}\right.$ $313.1333 \Delta \mathrm{Da} 0.005$, the identity of the ion was confirmed by the presence of a $\left[\mathrm{M}+\mathrm{Na}+\mathrm{CH}_{3} \mathrm{CN}\right]^{+}$adduct $\mathrm{m} / z$ 376.1569, a $[2 \mathrm{M}+\mathrm{H}]^{+}$and $\mathrm{a}[2 \mathrm{M}+\mathrm{Na}]^{+}$ion. Although levels of this metabolite increased in both genotypes in response to drought, this increase occurred earlier and was more consistent in Carrizo. In Cleopatra, only a moderate increase could be observed at 12 days of stress. 


\section{Non-stressful conditions}

To investigate the relationship of different basal concentrations of metabolites between genotypes on plant tolerance to stress, levels of hormones, phenylpropanoids and proline (Figure 8) were compared in control roots of both genotypes. Results indicated that Cleopatra plants showed higher basal levels of phenylpropanoids (cinnamic, coumaric, caffeic and ferulic acids ), proline and the hormones SA and IAA. However, Carrizo showed higher levels of JA and ABA under non-stressful conditions. Nontargeted analysis of metabolites showed more metabolites with higher peak intensity in roots of Cleopatra than in Carrizo. Among these, scopolin, a phenylpropanoid derivative, and the triterpenoid nomilin were tentatively annotated with a fold-change of 1.5 and 2.6 in Cleopatra over Carrizo, respectively (Supplementary material 7).

\section{Discussion}

In response to abiotic stress, plants alter their biochemical composition depending on the stress pressure and their relative tolerance to the adverse conditions (Arbona and others 2010, Ballizany and others 2012, Witt and others 2012). In a previous work, it was shown that when subjected to identical stress conditions, model plants Arabidopsis thaliana and Thellungiella halophila exhibited different amounts of secondary metabolites affected by the stress treatment with a low degree of overlapping among them whereas physiological and regulatory responses were almost identical (Arbona and others 2010). This could be explained in part by the fact that the two species used are not closely related, although both belong to the same family. In this sense, the phytochemical composition, especially secondary metabolism, is highly specific and different compounds might carry out the same protective and/or signaling function in different species (Arbona and others 2009a, Merchant and others 2006). 
In the present work, we used two genetically-related citrus genotypes widely used as rootstocks in modern citriculture. On one hand, Cleopatra mandarin with a high tolerance to salt stress due to the reduced $\mathrm{Na}^{+}$and $\mathrm{Cl}^{-}$uptake from roots to shoots associated to a low transpiration (Moya and others 2003). This trait is also associated to a constitutive tolerance to water deprivation due to reduced water uptake requirements. On the contrary, this ability to reduce transpiration seems to be detrimental under soil flooding conditions in which highly vigorous genotypes, such as Carrizo citrange or citrumelo have an advantage (Arbona and others 2008, Arbona and others 2009b). The contrasting physiological traits between Carrizo and Cleopatra that confer tolerance to either soil flooding or drought make these genotypes ideal to identify metabolic traits linked to sensitivity or tolerance to these abiotic constraints.

Under flooding conditions, roots of Carrizo plants (flooding-tolerant) accumulated much more proline than Cleopatra did whereas under drought, proline accumulated earlier and to a higher extent in roots of Cleopatra plants (drought-tolerant). These results could be explained by the fact that roots are the first organ sensing soil-derived adverse conditions and a higher ability to synthesize proline under stress situations could be behind a higher tolerance. However, in leaves, an opposite situation was found. Under similar flooding conditions, Arbona and others (2008) found that the proline concentration ratio between stressed and control plants was smaller in leaves of tolerant citrus genotypes than in sensitive ones. This was also true for model plants Arabidopsis thaliana and Thellungiella halophila under different stress conditions (Arbona and others 2010). In this scenario, it is likely that the higher proline accumulation in roots could act buffering the damaging effects of stress and, therefore, relieving the pressure exerted on leaves. 
The accumulation of phenylpropanoids over time was also studied in these two genotypes in response to the two environmental conditions. An accumulation of cinnamic acid in response to flooding in Cleopatra and in response to both stress treatments in Carrizo was observed. The results suggested an essential involvement of cinnamic acid in the responses of citrus to soil flooding but discarded its involvement in the tolerance mechanisms to this particular stress condition. However, in response to drought, the pattern observed in roots of Carrizo and Cleopatra might suggest its role as a defense compound under stress situations as this compound accumulated only in the sensitive genotype. In this sense, several authors (Dai and others 2012, Sun and others 2012) have recently reported that application of exogenous cinnamic acid to cucumber plants, increased endogenous levels as well as improved heat and drought stress tolerance. The apparent disagreement between data obtained from pretreatment on cucumber with this compound and its endogenous levels in citrus could be explained because the beneficial effect of the exogenous treatment was attributed to an improvement of the antioxidant activity. However, it has been shown that citrus possess an efficient antioxidant system (Arbona and others 2003, Arbona and others 2008). Therefore, it could be suggested that the moderate increase in cinnamic acid levels observed in Carrizo roots upon exposition to drought responds to a higher demand for antioxidant defenses associated to the higher sensitivity of this genotype.

In general, phenylpropanoid levels under non-stressful conditions were higher in Cleopatra than in Carrizo; therefore, it is likely that these higher levels prevent further induction of the phenylpropanoid biosynthetic pathway in the drought-tolerant genotype once the stress has been imposed. In addition, levels of the two metabolites annotated as phenylpropanoid derivatives increased in root tissue upon imposition of stress: a ferulic acid derivative and a hydroxycinnamyl alcohol glycoside synthesized from $p$-coumaric 
acid and involved in lignin biosynthesis. Lignification is an important stress response and its intensity is parallel to the stress pressure (Cabane and others 2012, Li and others 2012, Moura and others 2010). In a recent report, lignin deposition was reduced in mycorrhizal ryegrass plants subjected to drought compared to non-mycorrhizal plants (Lee and others 2012). In these experiments, mycorrhiza acted as attenuators of the stress pressure on plants, therefore reducing the requirement for lignin biosynthesis. In the present work, the data suggested that phenylpropanoid and lignin biosynthesis were activated in the two citrus genotypes subjected to either soil flooding or drought. However, similar increases in phenylpropanoids (especially cinnamic acid) and in the ferulic acid derivative were found in Carrizo and Cleopatra in response to soil flooding, indicating that this could be a specific response to soil waterlogging common to both genotypes. On the contrary, when subjected to drought only a consistent accumulation of cinnamic acid and hydroxycinnamyl alcohol glycoside was found in Carrizo, suggesting that the build-up of these compounds is dependent on stress pressure which is higher in the sensitive genotype.

In response to soil flooding, the parallel decrease in root $\mathrm{ABA}$ and $\mathrm{JA}$ concentration seems to be a common trend in the two genotypes independently of their different tolerance to this environmental cue (Arbona and Gómez-Cadenas 2008). However, under control conditions, plants of Carrizo had higher levels of both hormones than Cleopatra (Figure 8) indicating a different ABA and JA status prior to stress imposition. It could be then speculated that this different basal status could be behind the higher tolerance of Carrizo to soil flooding, as suggested in other species and stress conditions (Arbona et al. 2010). The observed reduction in the levels of both hormones has to be considered a stress response rather than a result of $\mathrm{O}_{2}$ depletion since other metabolites that require oxygen in their biosynthesis were not affected or even upregulated (e.g. see 
IAA or lignin precursors). The reduction of JA levels was concomitant with those of its biosynthetic precursor OPDA. Moreover, a molecule bearing an OPDA moiety showed an increasing pattern under flooding stress (Figure 6), suggesting that conjugation of OPDA could be an effective mechanism to reduce the availability of this precursor for JA biosynthesis. Although the identity of this molecule could not be confirmed, other types of OPDA and $d n$-OPDA conjugates have been identified in Arabidopsis thaliana (Glauser and others 2008); therefore it is not farfetched that similar compounds exist in other plant species. In response to drought, the pattern followed by JA and ABA was similar to that shown in leaves and roots of citrus in previous publications (Arbona and Gómez-Cadenas 2008, De Ollas and others 2012): a transient JA accumulation preceding ABA buildup. Although in De Ollas and others (2012), both the transient JA and progressive ABA accumulation were more pronounced. This is probably due to the experimental system used: water stress shock in De Ollas and others (2012) versus progressive dehydration in this work. Results of previous research also showed a progressive accumulation of IAA with stress (Arbona and Gómez-Cadenas 2008). The results presented in this work, confirm those previous results and extend the knowledge to different stress conditions. It has been recently described the induction of genes involved in IAA biosynthesis from tryptophan led to enhanced drought resistance (Lee and others 2012). Our results are compatible with the involvement of auxin in plant responses to drought, possibly by promoting root growth.

Secondary metabolite response was more intense in Cleopatra roots subjected to soil flooding than in Carrizo roots under the same conditions suggesting that a stronger induction of defense metabolites was required in this genotype to cope with this stress condition. A similar response was observed in Arabidopsis thaliana under simulated 
drought in comparison with the most tolerant Thellungiella halophila (Arbona and others 2010).

A higher number of mass chromatographic features showed only an early induction or repression in roots of Cleopatra plants subjected to drought whereas in Carrizo roots most metabolites accumulated much later (Supplementary Data 4 and 5). These results might indicate that metabolic responses to drought were faster in Cleopatra than in Carrizo. In addition, the lower degree of overlapping between the two genotypes and stress conditions indicates that different plant species have particular responses to stress, especially regarding to the secondary metabolism due to its high specificity (Arbona and others 2009a, Arbona and others 2010).

In addition to this, basal physiological and metabolic status of plants has to be considered an important stress tolerance factor as it is likely a combined process of both stress-induced responses and pre-existent defense mechanisms acting as 'priming' against stress (Arbona and others 2010, Mehterov and others 2012). For this reason, the basal metabolite configuration of Cleopatra and Carrizo under non-stressful conditions was investigated. Results from the non-targeted analysis indicated that Cleopatra had more potential metabolites with higher intensity than Carrizo under non-stressful conditions. Among which, the accumulation of a mass chromatographic feature annotated as scopolin, a phenylpropanoid derivative, suggested a redirection of the metabolic flow from cinnamic acid. Moreover, results of targeted analyses showed that, with the exception of $\mathrm{ABA}$ and JA, levels of the rest of metabolites (proline, IAA and phenylpropanoids) in roots of non-stressed plants were higher in Cleopatra than in Carrizo. This suggests that higher basal levels of proline, IAA and phenylpropanoids are involved in drought tolerance whereas higher levels of ABA and JA are involved in soil flooding tolerance. Our results are in agreement with previous findings in Arabidopsis 
thaliana, where the overexpression of genes involved in ABA signaling resulted in enhanced waterlogging tolerance (Liu and others 2012).

Taken together, results presented in this work suggest the involvement of proline and phenylpropanoids, as well as their derivatives, in the response of citrus to water and flooding stress. The analysis of the hormonal levels revealed a parallel pattern of ABA and JA in response to water stress and confirmed previous observations that showed a strong decrease in their levels in response to soil flooding. To this respect, downregulation of JA biosynthesis under soil flooding stress should be associated to the repression of lipoxygenase and/or the conjugation of the precursor OPDA. Other regulation processes that involve IAA could be oriented towards the production of new roots to cope with the limitation of water availability induced by flooding and drought as suggested by Lee and others (2012). The study of the plant metabolome under stressful conditions indicated a low degree of overlapping in the metabolites altered by the stress treatment in the two genotypes considered, allowing the identification of abiotic stress-responsive metabolites in citrus for the first time, as far as we know. This result was associated with the specificity of the secondary metabolism in citrus, put forward by Arbona and others (2009a), and also the different stress tolerance of Cleopatra and Carrizo. When exploring the metabolite levels under non-stressful conditions scopolin, a phenylpropanoid derivative, nomilin, a triterpenoid, and hydroxycinnamyl alcohol glycoside were identified as potential stress-tolerance markers in Cleopatra and Carrizo, respectively. In addition, the higher concentrations of proline, IAA and phenylpropanoids together with the higher number of putative metabolites found in roots of non-stressed Cleopatra plants could be an effective physiological mechanism preventing or delaying drought-derived damage but not soil flooding. 
Instead, higher ABA and JA levels in roots could be behind the higher tolerance of Carrizo to soil flooding.

\section{Acknowledgements}

This work was supported by the Spanish Ministerio de Economía y Competitividad (MINECO) and Universitat Jaume I/Fundació Bancaixa through grants No. AGL201022195-C03-01/AGR and P11B2009-01, respectively. V. A. was recipient of a "Ramón y Cajal" contract from the MINECO. Mass Spectrometry analyses were performed at the central facilities (Servei Central d'Instrumentació Científica, SCIC) of Universitat Jaume I

\section{Conflict of interest}

The authors declare that they have no conflict of interest. 


\section{References}

Arbona V, Argamasilla R, Gómez-Cadenas A (2010) Common and divergent physiological, hormonal and metabolic responses of Arabidopsis thaliana and Thellungiella halophila to water and salt stress. J Plant Physiol 167:1342-1350

Arbona V, Iglesias DJ, Talón M, Gómez-Cadenas A (2009a) Plant phenotype demarcation using nontargeted LC-MS and GC-MS metabolite profiling. J Agric Food Chem 57:7338-7347

Arbona V, López-Climent MF, Pérez-Clemente RM, Gómez-Cadenas A (2009b) Maintenance of a high photosynthetic performance is linked to flooding tolerance in citrus. Environ Exp Bot 66:135-142

Arbona V, Gómez-Cadenas A (2008) Hormonal modulation of citrus responses to flooding. J Plant Growth Regul 27:241-250

Arbona V, Hossain Z, López-Climent MF, Pérez-Clemente RM, Gómez-Cadenas A (2008) Antioxidant enzymatic activity is linked to waterlogging stress tolerance in citrus. Physiol Plant 132:452-466

Arbona V, Lopez-Climent MF, Mahouachi J, Perez-Clemente RM, Abrams SR, Gomez-Cadenas A (2006) Use of persistent analogs of abscisic acid as palliatives against salt-stress induced damage in citrus plants. J Plant Growth Regul 25:1-9

Arbona V, Flors V, Jacas J, Garcia-Agustin P, Gomez-Cadenas A (2003) Enzymatic and non-enzymatic antioxidant responses of Carrizo citrange, a salt-sensitive citrus rootstock, to different levels of salinity. Plant Cell Physiol 44:388-394 
Ballizany WL, Hofmann RW, Jahufer MZZ, Barrett BA (2012) Genotypexenvironment analysis of flavonoid accumulation and morphology in white clover under contrasting field conditions. Field Crops Res 128:156-166

Bates LS, Waldren RP, Teare ID (1973) Rapid determination of free proline for water-stress studies. Plant Soil 39:205-207

Cabane M, Afif D, Hawkins S (2012) Lignins and abiotic stresses. Adv Bot Res 61:219-262

Cidade LC, de Oliveira TM, Mendes AFS, Macedo AF, Floh EIS, Gesteira AS, Soares-Filho WS, Costa MGC (2012) Ectopic expression of a fruit phytoene synthase from Citrus paradisi Macf. promotes abiotic stress tolerance in transgenic tobacco. Mol Biol Rep:1-9

Dai A, Nie Y, Yu B, Li Q, Lu L, Bai J (2012) Cinnamic acid pretreatment enhances heat tolerance of cucumber leaves through modulating antioxidant enzyme activity. Environ Exp Bot 79:1-10

De Ollas C, Hernando B, Arbona V, Gómez-Cadenas A (2012) Jasmonic acid transient accumulation is needed for abscisic acid increase in citrus roots under drought stress conditions. Physiol Plant in press doi:10.1111/j.13993054.2012.01659.x

Des Marais DL, Juenger TE (2010) Pleiotropy, plasticity, and the evolution of plant abiotic stress tolerance. Ann New York Acad Sci 1206:56-79 
Djoukeng JD, Arbona V, Argamasilla R, Gómez-Cadenas A (2008) Flavonoid profiling in leaves of citrus genotypes under different environmental situations. J Agric Food Chem 56:11087-11097

Durgbanshi A, Arbona V, Pozo O, Miersch O, Sancho JV, Gómez-Cadenas A (2005) Simultaneous determination of multiple phytohormones in plant extracts by liquid chromatography-electrospray tandem mass spectrometry. J Agric Food Chem $53: 8437-8442$

Glauser G, Grata E, Rudaz S, Wolfender J- (2008) High-resolution profiling of oxylipin-containing galactolipids in Arabidopsis extracts by ultra-performance liquid chromatography/time-of-flight mass spectrometry. Rapid Commun Mass Spectrom 22:3154-3160

Gómez-Cadenas A, Pozo OJ, Garcia-Augustin P, Sancho JV (2002) Direct analysis of abscisic acid in crude plant extracts by liquid chromatographyelectrospray/tandem mass spectrometry. Phytochem Anal 13:228-234

Gómez-Cadenas A, Tadeo FR, Talon M, Primo-Millo E (1996) Leaf abscission induced by ethylene in water-stressed intact seedlings of Cleopatra mandarin requires previous abscisic acid accumulation in roots. Plant Physiol 112:401-408

Kristl J, Veber M, Krajničič B, Orešnik K, Slekovec M (2005) Determination of jasmonic acid in Lemna minor (L.) by liquid chromatography with fluorescence detection. Anal Bioanal Chem 383:886-893

Lee B, Muneer S, Jung W, Avice J, Ourry A, Kim T (2012) Mycorrhizal colonization alleviates drought-induced oxidative damage and lignification in the 
leaves of drought-stressed perennial ryegrass (Lolium perenne). Physiol Plant $145: 440-449$

Lee M, Jung J-, Han D-, Seo PJ, Park WJ, Park C- (2012) Activation of a flavin monooxygenase gene YUCCA7 enhances drought resistance in Arabidopsis. Planta 235:923-938

Li Z, Peng Y, Ma X (2012) Different response on drought tolerance and postdrought recovery between the small-leafed and the large-leafed white clover (Trifolium repens L.) associated with antioxidative enzyme protection and lignin metabolism. Acta Physiol Plant 35: 213-222

Liu P, Sun F, Gao R, Dong H (2012) RAP2.6L overexpression delays waterlogging induced premature senescence by increasing stomatal closure more than antioxidant enzyme activity. Plant Mol Biol 79:609-622

López-Climent MF, Arbona V, Pérez-Clemente RM, Gómez-Cadenas A (2008) Relationship between salt tolerance and photosynthetic machinery performance in citrus. Environ Exp Bot 62:176-184

Mehterov N, Balazadeh S, Hille J, Toneva V, Mueller-Roeber B, Gechev T (2012) Oxidative stress provokes distinct transcriptional responses in the stress-tolerant atr7 and stress-sensitive loh2 Arabidopsis thaliana mutants as revealed by multiparallel quantitative real-time PCR analysis of ROS marker and antioxidant genes. Plant Physiol Biochem 59: 20-29 
Merchant A, Richter A, Popp M, Adams M (2006) Targeted metabolite profiling provides a functional link among eucalypt taxonomy, physiology and evolution. Phytochemistry 67:402-408

Moura JCMS, Bonine CAV, de Oliveira Fernandes Viana J, Dornelas MC, Mazzafera P (2010) Abiotic and biotic stresses and changes in the lignin content and composition in plants. J Integr Plant Biol 52:360-376

Moya JL, Gómez-Cadenas A, Primo-Millo E, Talon M (2003) Chloride absorption in salt-sensitive Carrizo citrange and salt-tolerant Cleopatra mandarin citrus rootstocks is linked to water use. J Exp Bot 54:825-833

Munns R (2011) Plant adaptations to salt and water stress: differences and commonalities. Adv Bot Res 57:1-32

Qin F, Shinozaki K, Yamaguchi-Shinozaki K (2011) Achievements and challenges in understanding plant abiotic stress responses and tolerance. Plant Cell Physiol $52: 1569-1582$

Sun W, Nie Y, Gao Y, Dai A, Bai J (2012) Exogenous cinnamic acid regulates antioxidant enzyme activity and reduces lipid peroxidation in drought-stressed cucumber leaves. Acta Physiol Plant 34:641-655

Vincent D, Lapierre C, Pollet B, Cornic G, Negroni L, Zivy M (2005) Water deficits affect caffeate O-methyltransferase, lignification, and related enzymes in maize leaves. A proteomic investigation. Plant Physiol 137:949-960 
Witt S, Galicia L, Lisec J, Cairns J, Tiessen A, Araus JL, Palacios-Rojas N, Fernie AR (2012) Metabolic and phenotypic responses of greenhouse-grown maize hybrids to experimentally controlled drought stress. Mol Plant 5:401-417 


\section{Figure legends}

Figure 1. Root proline content (expressed as $\log _{2}$ (stress/control)) in Cleopatra mandarin (a) and Carrizo citrange (b) subjected to soil flooding and water stress. Asterisks denote significant difference at $p \leq 0.05$ between control and stressed samples.

Figure 2. Phenylpropanoid content (expressed as $\log _{2}($ stress/control)) in roots of Cleopatra mandarin (a) and Carrizo citrange (b) subjected to soil flooding and water stress. Asterisks denote significant difference at $p \leq 0.05$ between control and stressed samples.

Figure 3. Abscisic (ABA) and jasmonic acid (JA) levels (expressed as $\log _{2}($ stress/control) $)$ in roots of Cleopatra mandarin (a) and Carrizo citrange (b) subjected to soil flooding and water stress. Asterisks denote significant difference at $p \leq 0.05$ between control and stressed samples.

Figure 4. Indole-3-acetic (IAA) levels (expressed as $\log _{2}$ (stress/control)) in roots of Cleopatra mandarin (a) and Carrizo citrange (b) subjected to soil flooding and water stress. Asterisks denote significant difference at $p \leq 0.05$ between control and stressed samples.

Figure 5. Venn diagrams depicting the degree of overlapping between metabolites altered in Carrizo citrange and Cleopatra mandarin subjected to soil flooding (a) and drought (b).

Figure 6. Differential metabolites commonly affected in roots of Cleopatra mandarin and Carrizo citrange subjected to soil flooding (expressed as $\log _{2}$ (stress/control)). Asterisks denote significant difference at $p \leq 0.05$ between control and stressed samples. 
Figure 7. Differential metabolites commonly affected in roots of Cleopatra mandarin and Carrizo citrange subjected to water stress (expressed as $\log _{2}$ (stress/control)). Asterisks denote significant difference at $p \leq 0.05$ between control and stressed samples.

Figure 8. Metabolite differences between roots of Cleopatra mandarin (CM) and Carrizo citrange (CC) control plants. Proline, phenylpropanoids and plant hormone contents expressed as $\log _{2}(\mathrm{CM} / \mathrm{CC})$. Asterisks denote significant difference at $p \leq 0.05$ between $\mathrm{CM}$ and $\mathrm{CC}$ control samples.

\section{Supplementary Data}

Supplementary Data 1. Assessment of reproducibility for metabolomics assays

Supplementary Data 2. Assessment of linearity in Carrizo citrange

Supplementary Data 3. Assessment of linearity in Cleopatra mandarin

Supplementary Data 4. Differential metabolite profiles in Carrizo citrange (a) and Cleopatra mandarin (b) subjected to soil flooding stress.

Supplementary Data 5. Differential metabolite profiles in Carrizo citrange (a) and Cleopatra mandarin (b) subjected to drought.

Supplementary Data 6. Mass chromatographic features with area values higher in Carrizo citrange than Cleopatra mandarin non-stressed plants.

Supplementary Data 7. Mass chromatographic features with area values higher in Cleopatra mandarin than Carrizo citrange non-stressed plants. 


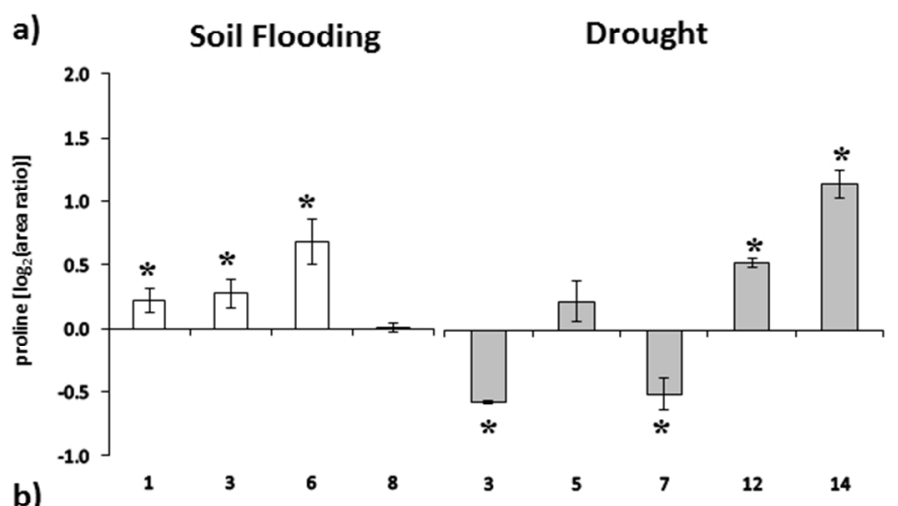

b)

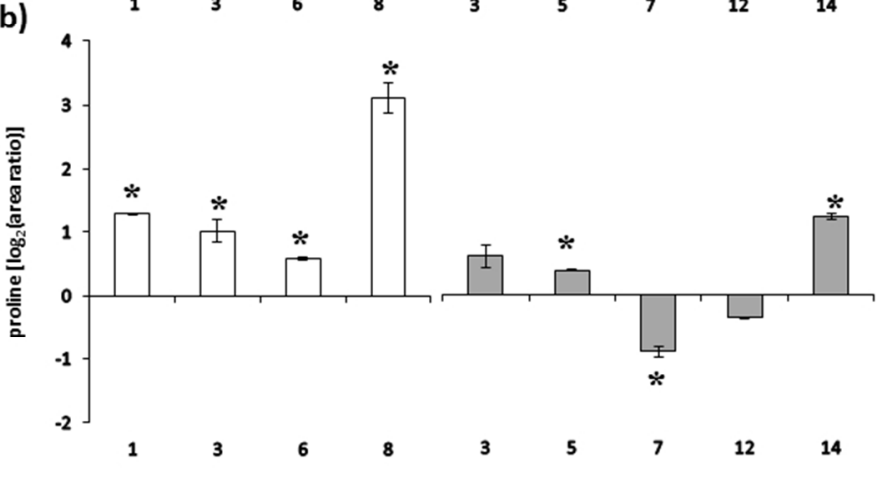

Days after stress imposition

Figure 1. Root proline content (expressed as $\log _{2}$ (stress/control)) in Cleopatra mandarin (a) and Carrizo citrange (b) subjected to soil flooding and water stress. Asterisks denote significant difference at $p \leq 0.05$ between control and stressed samples. $190 \times 275 \mathrm{~mm}(96 \times 96 \mathrm{DPI})$ 
a)
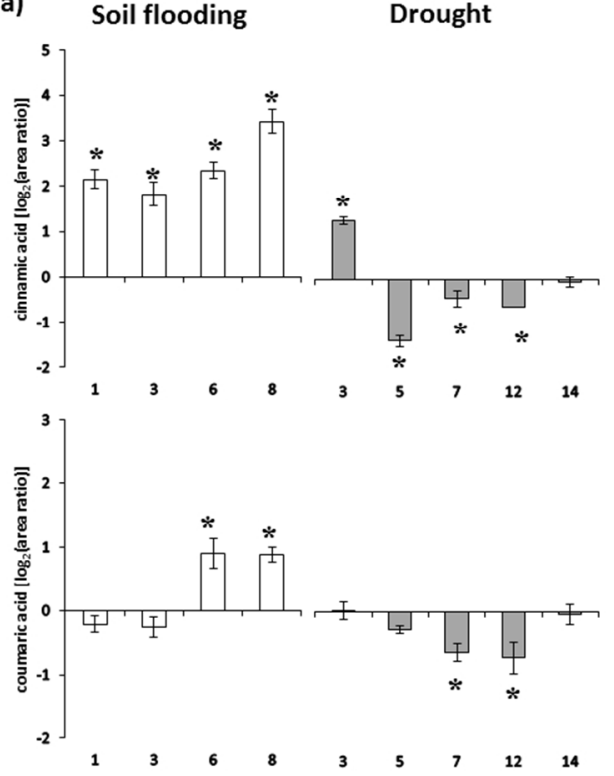

b) Soil flooding
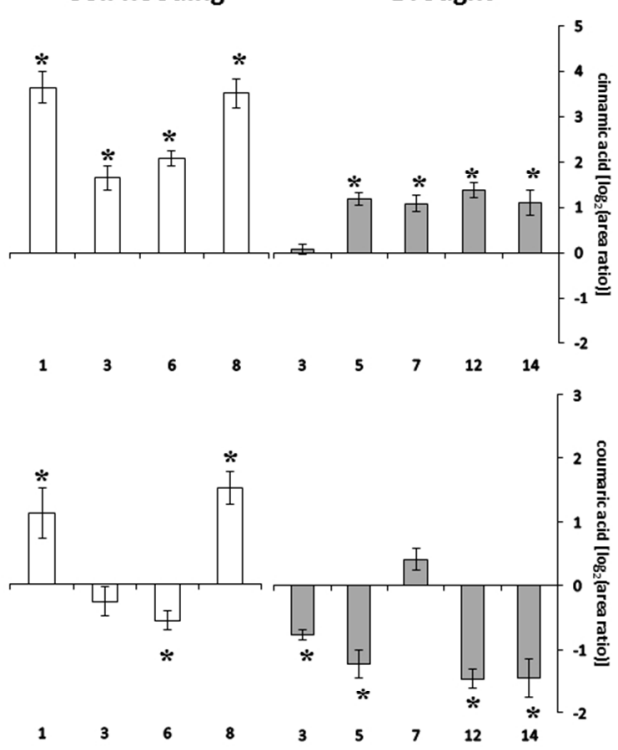

Days after stress imposition

Figure 2. Phenylpropanoid content (expressed as $\log _{2}$ (stress/control)) in roots of Cleopatra mandarin (a) and Carrizo citrange (b) subjected to soil flooding and water stress. Asterisks denote significant difference at $\mathrm{p} \leq 0.05$ between control and stressed samples.

$275 \times 190 \mathrm{~mm}(96 \times 96 \mathrm{DPI})$ 


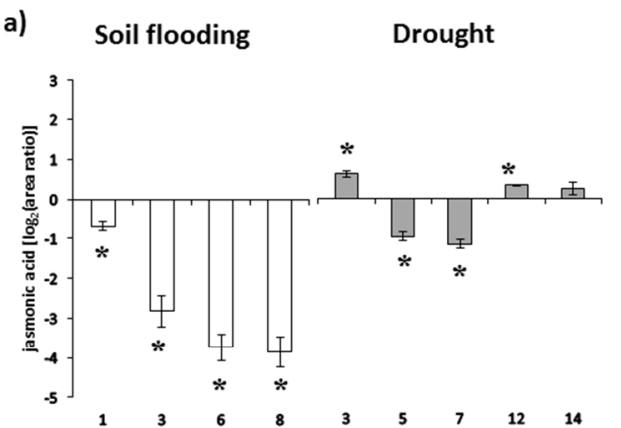

b) Soil flooding

Drought
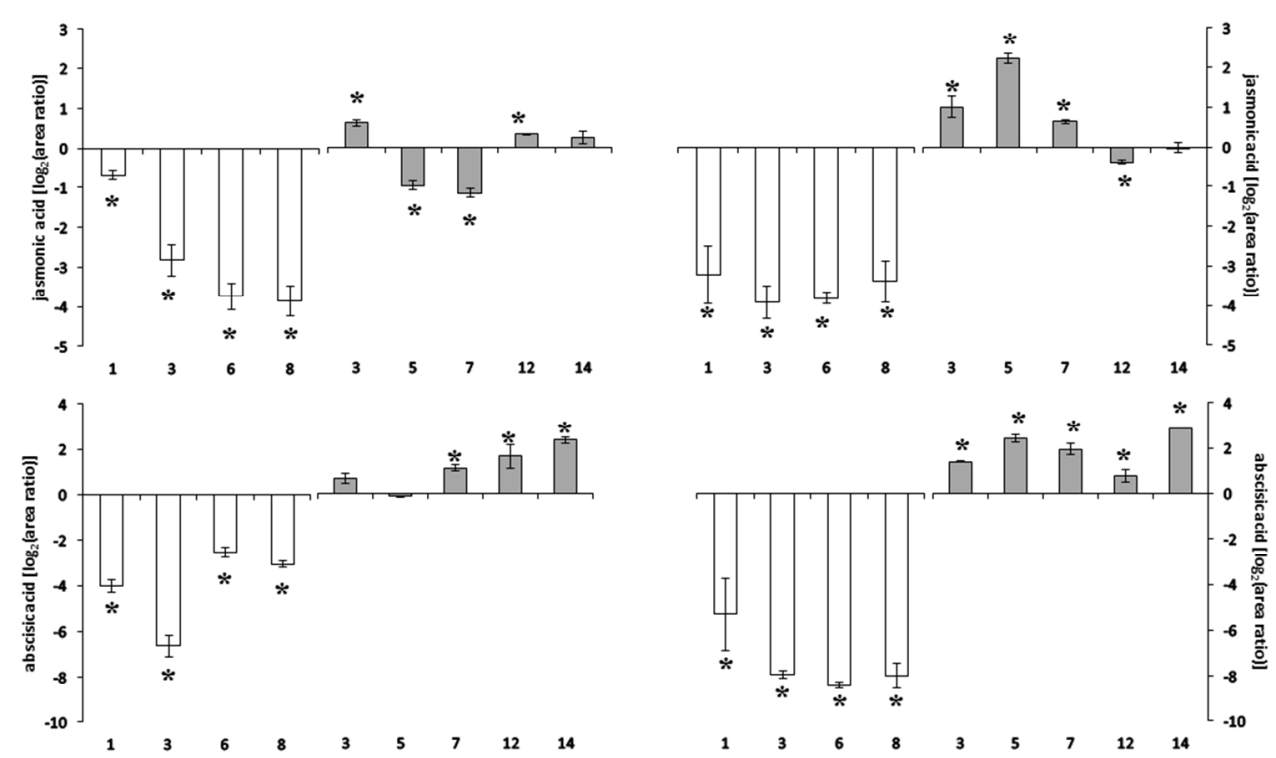

Days after stress imposition

Figure 3. Abscisic (ABA) and jasmonic acid (JA) levels (expressed as $\log _{2}$ (stress/control)) in roots of Cleopatra mandarin (a) and Carrizo citrange (b) subjected to soil flooding and water stress. Asterisks denote significant difference at $\mathrm{p} \leq 0.05$ between control and stressed samples. $275 \times 190 \mathrm{~mm}(96 \times 96 \mathrm{DPI})$ 
b)

Soil flooding

Drought
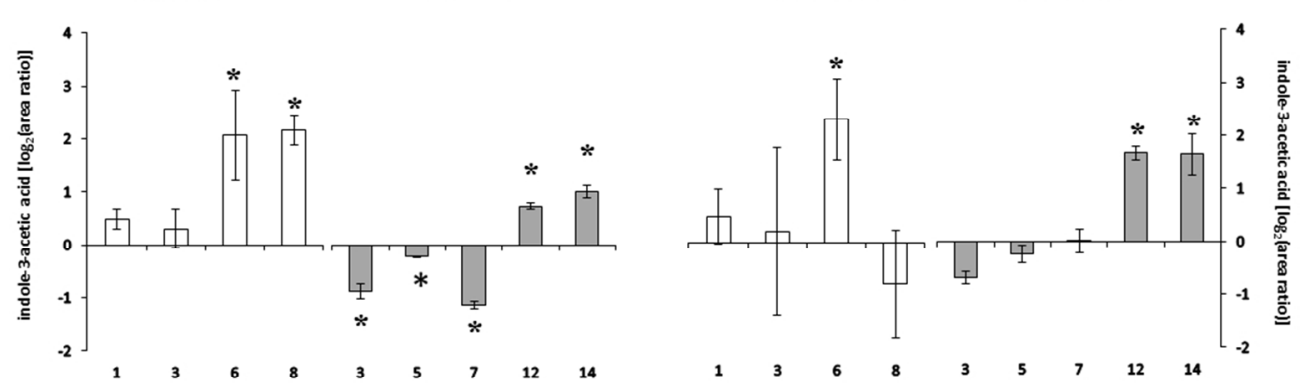

Days after stress imposition

Figure 4. Indole-3-acetic (IAA) levels (expressed as $\log _{2}$ (stress/control)) in roots of Cleopatra mandarin (a) and Carrizo citrange (b) subjected to soil flooding and water stress. Asterisks denote significant difference at $\mathrm{p} \leq 0.05$ between control and stressed samples. $275 \times 190 \mathrm{~mm}(96 \times 96 \mathrm{DPI})$ 
a) Carrizo citrange Cleopatramandarin

b)

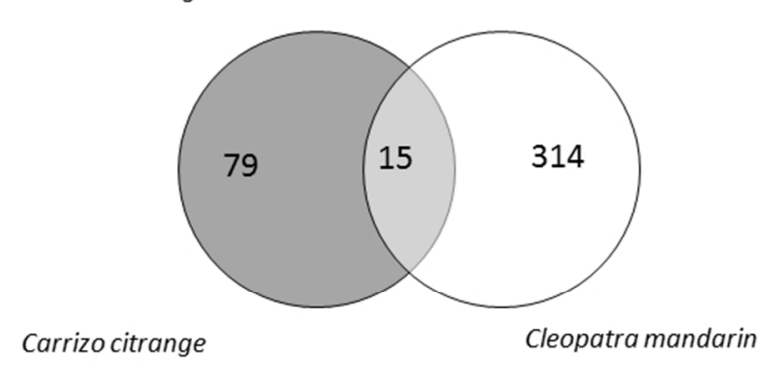

Figure 5. Venn diagrams depicting the degree of overlapping between metabolites altered in Carrizo citrange and Cleopatra mandarin subjected to soil flooding (a) and drought (b). $190 \times 275 \mathrm{~mm}(96 \times 96 \mathrm{DPI})$ 
Figure 6. Differential metabolites commonly affected in roots of Cleopatra mandarin and Carrizo citrange subjected to soil flooding (expressed as $\log _{2}$ (stress/control)). Asterisks denote significant difference at $\mathrm{p} \leq 0.05$ between control and stressed samples. $190 \times 275 \mathrm{~mm}(96 \times 96 \mathrm{DPI})$ 
Figure 7. Differential metabolites commonly affected in roots of Cleopatra mandarin and Carrizo citrange subjected to water stress (expressed as $\log _{2}$ (stress/control)). Asterisks denote significant difference at $\mathrm{p} \leq 0.05$ between control and stressed samples. $190 \times 275 \mathrm{~mm}(96 \times 96 \mathrm{DPI})$ 
Figure 8. Metabolite differences between roots of Cleopatra mandarin (CM) and Carrizo citrange (CC) control plants. Proline, phenylpropanoids and plant hormone contents expressed as $\log _{2}(\mathrm{CM} / \mathrm{CC})$. Asterisks denote significant difference at $\mathrm{p} \leq 0.05$ between $\mathrm{CM}$ and CC control samples. $190 \times 275 \mathrm{~mm}(96 \times 96 \mathrm{DPI})$ 
Supplementary Data 1. Assessment of reproducibility for metabolomics assays

1. Analysis of Selected Features. Cleopatra mandarin

\subsection{Selection of Analytes}

\begin{tabular}{ccccc}
\hline No. & $\boldsymbol{m} / \boldsymbol{z}$ & Adduct & $\mathbf{t}_{\mathbf{r}}(\mathbf{m i n})$ & {$[\mathbf{M}]$} \\
\hline $\mathbf{1}$ & 501.15195 & {$[\mathrm{M}+\mathrm{H}]^{+}$} & 10.85 & 500.14753 \\
$\mathbf{2}$ & 258.11094 & {$\left[\mathrm{M}+\mathrm{H}-\mathrm{C}_{6} \mathrm{H}_{10} \mathrm{O}_{5}\right]^{+}$} & 14.07 & 419.15854 \\
$\mathbf{3}$ & 549.21125 & {$[\mathrm{M}+\mathrm{H}]^{+}$} & 18.11 & 548.20707 \\
$\mathbf{4}$ & 286.10803 & {$[\mathrm{M}+\mathrm{H}]^{+}$} & 21.6 & 285.10281 \\
$\mathbf{5}$ & 272.12856 & {$[2 \mathrm{M}+\mathrm{H}]^{+}$} & 25.98 & 135.56265 \\
$\mathbf{6}$ & 410.1579 & {$[\mathrm{M}+\mathrm{Na}]^{+}$} & 30.45 & 387.17113 \\
$\mathbf{7}$ & 346.14647 & {$[\mathrm{M}+\mathrm{H}]^{+}$} & 32.01 & 345.13956 \\
$\mathbf{8}$ & 245.09892 & {$[\mathrm{M}+\mathrm{H}]^{+}$} & 32.6 & 244.08979 \\
$\mathbf{9}$ & 310.17995 & {$[\mathrm{M}+\mathrm{H}]^{+}$} & 33.26 & 309.17534 \\
$\mathbf{1 0}$ & 286.14034 & {$[2 \mathrm{M}+\mathrm{H}]^{+}$} & 34.1 & 142.56881 \\
\hline
\end{tabular}

1.2. Reproducibility of retention time

\begin{tabular}{ccc}
\hline No. & $\begin{array}{c}\text { extraction rep's (N=16) } \\
\text { RSD (\%) }\end{array}$ & $\begin{array}{c}\text { injection rep's (n=16) } \\
\text { RSD (\%) }\end{array}$ \\
\hline $\mathbf{1}$ & 0.4 & 0.27 \\
$\mathbf{2}$ & 0.19 & 0.15 \\
$\mathbf{3}$ & 0.1 & 0.13 \\
$\mathbf{4}$ & 0.14 & 0.09 \\
$\mathbf{5}$ & 0.12 & 0.09 \\
$\mathbf{6}$ & 0.08 & 0.05 \\
$\mathbf{7}$ & 0.09 & 0.06 \\
$\mathbf{8}$ & 0.1 & 0.06 \\
$\mathbf{9}$ & 0.08 & 0.04 \\
$\mathbf{1 0}$ & 0.08 & 0.05 \\
\hline average & $0.14 \pm 0.10$ & $0.10 \pm 0.07$ \\
sd & &
\end{tabular}

\subsection{Reproducibility of peak intensities}

\begin{tabular}{ccc}
\hline No. & $\begin{array}{c}\text { extraction rep's (N=16) } \\
\text { RSD (\%) }\end{array}$ & $\begin{array}{c}\text { injection rep's (n=16) } \\
\text { RSD (\%) }\end{array}$ \\
\hline $\mathbf{1}$ & 37.91 & 19.28 \\
$\mathbf{2}$ & 11.01 & 2.74 \\
$\mathbf{3}$ & 12.81 & 2.29 \\
$\mathbf{4}$ & 13.22 & 4.08 \\
$\mathbf{5}$ & 16.33 & 4.48 \\
$\mathbf{6}$ & 10.81 & 2.41 \\
$\mathbf{7}$ & 8.92 & 4.25 \\
$\mathbf{8}$ & 3.68 & 1.75
\end{tabular}




\begin{tabular}{ccc}
$\mathbf{9}$ & 13.12 & $\begin{array}{l}2.79 \\
\mathbf{1 0}\end{array}$ \\
\hline $\begin{array}{c}\text { average } \\
\pm s d\end{array}$ & 13.91 & 5.06 \\
\hline \multirow{2}{*}{$13.67 \pm 9.17$} & $4.92 \pm 5.17$
\end{tabular}

1.4. Mass accuracy

\begin{tabular}{|c|c|c|c|c|}
\hline No. & $\exp [\mathbf{M}]$ & $\begin{array}{c}\text { Calculated elemental } \\
\text { composition }\end{array}$ & $\begin{array}{c}\text { th }[\mathbf{M}] \\
\text { (Pubchem) }\end{array}$ & $\begin{array}{c}\text { mass } \\
\text { deviation } \\
(\mathrm{mDa})\end{array}$ \\
\hline 1 & 500.14753 & $\mathrm{C}_{30} \mathrm{H}_{28} \mathrm{O}_{3} \mathrm{~S}_{2}$ & 500.147978 & 0.4 \\
\hline 2 & 419.15854 & $\mathrm{C}_{15} \mathrm{H}_{21} \mathrm{~N}_{11} \mathrm{O}_{2} \mathrm{~S}$ & 419.160033 & 1.5 \\
\hline 3 & 548.20707 & $\mathrm{C}_{13} \mathrm{H}_{37} \mathrm{~N}_{6} \mathrm{O}_{15} \mathrm{P}$ & 548.205442 & 1.6 \\
\hline 4 & 285.10281 & $\mathrm{C}_{13} \mathrm{H}_{19} \mathrm{NO}_{4} \mathrm{~S}$ & 285.103473 & 0.7 \\
\hline 5 & 135.56265 & & - & - \\
\hline 6 & 387.17113 & $\mathrm{C}_{10} \mathrm{H}_{25} \mathrm{~N}_{7} \mathrm{O}_{9}$ & 387.171368 & 0.2 \\
\hline 7 & 345.13956 & $\mathrm{C}_{10} \mathrm{H}_{23} \mathrm{~N}_{3} \mathrm{O}_{10}$ & 345.138338 & 1.2 \\
\hline 8 & 244.08979 & & & \\
\hline 9 & 309.17534 & $\mathrm{C}_{17} \mathrm{H}_{27} \mathrm{NO}_{2} \mathrm{~S}$ & 309.17624 & 0.9 \\
\hline 10 & 142.56881 & & & \\
\hline
\end{tabular}

(-) not calculated 
2. Analysis of Selected Features. Carrizo citrange

\subsection{Selection of Analytes}

\begin{tabular}{ccccc}
\hline analyte & $\boldsymbol{m} / \mathbf{z}$ & Adduct & $\mathbf{t}_{\mathbf{r}}(\mathbf{m i n})$ & {$[\mathbf{M}]$} \\
\hline $\mathbf{1}$ & 324.15611 & {$[\mathrm{M}+\mathrm{H}]^{+}$} & 24.13 & 323.15157 \\
$\mathbf{2}$ & 326.17072 & {$[\mathrm{M}+\mathrm{H}]^{+}$} & 27.73 & 325.16567 \\
$\mathbf{3}$ & 517.19022 & {$[\mathrm{M}+\mathrm{H}]^{+}$} & 30.3 & 516.18667 \\
$\mathbf{4}$ & 410.15886 & {$[\mathrm{M}+\mathrm{NH}]^{+}$} & 30.44 & 392.12783 \\
$\mathbf{5}$ & 284.12665 & {$[\mathrm{M}+\mathrm{H}]^{+}$} & 31.55 & 283.12272 \\
$\mathbf{6}$ & 310.17627 & {$[\mathrm{M}+\mathrm{H}]^{+}$} & 33.22 & 309.17438 \\
$\mathbf{7}$ & 376.15404 & {$[\mathrm{M}+\mathrm{Na}]^{+}$} & 34.4 & 353.16346 \\
$\mathbf{8}$ & 390.16933 & {$[\mathrm{M}+\mathrm{Na}]^{+}$} & 39.73 & 367.18189 \\
$\mathbf{9}$ & 762.4139 & {$[\mathrm{M}+\mathrm{H}]^{+}$} & 45.57 & 761.41035 \\
$\mathbf{1 0}$ & 444.21327 & {$[\mathrm{M}+\mathrm{Na}]^{+}$} & 45.58 & 421.22782 \\
\hline
\end{tabular}

\subsection{Reproducibility of retention time}

\begin{tabular}{ccc}
\hline no. & $\begin{array}{c}\text { extraction rep's (N=16) } \\
\text { RSD (\%) }\end{array}$ & $\begin{array}{c}\text { injection rep's (n=16) } \\
\text { RSD (\%) }\end{array}$ \\
\hline $\mathbf{1}$ & 0.05 & 0.07 \\
$\mathbf{2}$ & 0.03 & 0.07 \\
$\mathbf{3}$ & 0.06 & 0.13 \\
$\mathbf{4}$ & 0.06 & 0.08 \\
$\mathbf{5}$ & 0.12 & 0.14 \\
$\mathbf{6}$ & 0.04 & 0.07 \\
$\mathbf{7}$ & 0.08 & 0.11 \\
$\mathbf{8}$ & 0.23 & 0.15 \\
$\mathbf{9}$ & 0.06 & 0.09 \\
$\mathbf{1 0}$ & 0.09 & 0.09 \\
\hline average \pm & $0.08 \pm 0.06$ & $0.10 \pm 0.03$ \\
sd & &
\end{tabular}

\subsection{Reproducibility of peak intensities}

\begin{tabular}{ccc}
\hline no. & $\begin{array}{c}\text { extraction rep's (N=16) } \\
\text { RSD (\%) }\end{array}$ & $\begin{array}{c}\text { injection rep's (n=16) } \\
\text { RSD (\%) }\end{array}$ \\
\hline 1 & 13.96 & 12.84 \\
2 & 19.37 & 11.29 \\
3 & 17.32 & 10.01 \\
4 & 6.6 & 9.63 \\
5 & 9.31 & 8.17 \\
6 & 10.54 & 11.73 \\
7 & 3.76 & 10.46 \\
8 & 2.15 & 9.32 \\
9 & 12.81 & 10.55 \\
10 & 3.17 & 11.46 \\
\hline
\end{tabular}




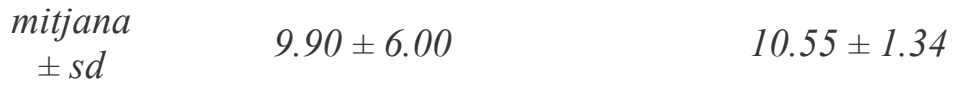

\subsection{Mass accuracy}

\begin{tabular}{|c|c|c|c|c|}
\hline No. & $\exp [\mathbf{M}]$ & $\begin{array}{l}\text { Calculated elemental } \\
\text { composition }\end{array}$ & $\begin{array}{c}\text { th }[\mathbf{M}] \\
\text { (Pubchem) }\end{array}$ & $\begin{array}{l}\text { mass deviation } \\
(\mathrm{mDa})\end{array}$ \\
\hline 1 & 323.15157 & $\mathrm{C}_{20} \mathrm{H}_{21} \mathrm{NO}_{3}$ & 323.152136 & 0.5 \\
\hline 2 & 325.16567 & $\mathrm{C}_{12} \mathrm{H}_{27} \mathrm{~N}_{3} \mathrm{O}_{5} \mathrm{~S}$ & 325.167133 & 1.5 \\
\hline 3 & 516.18667 & $\mathrm{C}_{9} \mathrm{H}_{24} \mathrm{~N}_{16} \mathrm{O}_{10}$ & 516.186124 & 0.5 \\
\hline 4 & 392.12783 & $\mathrm{C}_{7} \mathrm{H}_{17} \mathrm{~N}_{14} \mathrm{O}_{4} \mathrm{P}$ & 392.129477 & 1.6 \\
\hline 5 & 283.12272 & $\mathrm{C}_{9} \mathrm{H}_{23} \mathrm{~N}_{3} \mathrm{O}_{3} \mathrm{P}_{2}$ & 283.121459 & 1.3 \\
\hline 6 & 309.17438 & $\mathrm{C}_{20} \mathrm{H}_{23} \mathrm{NO}_{2}$ & 309.17287 & 1.5 \\
\hline 7 & 353.16346 & $\mathrm{C}_{13} \mathrm{H}_{29} \mathrm{~N}_{3} \mathrm{O}_{4} \mathrm{P}_{2}$ & 353.163321 & 0.1 \\
\hline 8 & 367.18189 & $\mathrm{C}_{12} \mathrm{H}_{36} \mathrm{NO}_{5} \mathrm{P}_{3}$ & 367.180624 & 1.3 \\
\hline 9 & 761.41035 & $\mathrm{C}_{18} \mathrm{H}_{53} \mathrm{~N}_{25} \mathrm{O}_{5} \mathrm{P}_{2}$ & 761.413655 & 3.3 \\
\hline 10 & 421.22782 & $\mathrm{C}_{10} \mathrm{H}_{28} \mathrm{~N}_{15} \mathrm{O}_{2} \mathrm{P}$ & 421.228792 & 1.0 \\
\hline
\end{tabular}




\section{Supplementary Data 2.}

\section{Assessment of linearity - Carrizo citrange}

Compound 1: 1

\begin{tabular}{|c|c|c|c|c|}
\hline RT & & & Average & SE \\
\hline 1 & 24.18 & 74.551 & 104.960333 & 18.3335732 \\
\hline 2 & 24.17 & 168.694 & 233.852 & 38.9779412 \\
\hline 3 & 24.13 & 337.754 & 463.782333 & 69.9616663 \\
\hline 4 & 24.15 & 714.064 & 891.655667 & 105.869764 \\
\hline 5 & 24.15 & 1298.78 & 1563.04233 & 141.388374 \\
\hline 6 & 24.16 & 2386.893 & 2706.19933 & 168.085616 \\
\hline 7 & 24.16 & 102.422 & & \\
\hline 8 & 24.16 & 229.368 & & \\
\hline 9 & 24.15 & 474.151 & & \\
\hline 10 & 24.16 & 880.596 & & $1: 32$ \\
\hline 11 & 24.18 & 1608.018 & & $1: 16$ \\
\hline 12 & 24.14 & 2774.798 & & $1: 8$ \\
\hline 13 & 24.17 & 137.908 & & $1: 4$ \\
\hline 14 & 24.18 & 303.494 & & $1: 2$ \\
\hline 15 & 24.2 & 579.442 & & $1: 1$ \\
\hline 16 & 24.19 & 1080.307 & & \\
\hline 17 & 24.16 & 1782.329 & & \\
\hline 18 & 24.16 & 2956.907 & & \\
\hline
\end{tabular}

Compound 2: 2

\begin{tabular}{|c|c|c|c|c|}
\hline RT & & & Average & SE \\
\hline 1 & 27.78 & 99.541 & 135.74 & 22.0032544 \\
\hline 2 & 27.74 & 217.991 & 278.142 & 34.9879469 \\
\hline 3 & 27.74 & 442.961 & 550.285 & 58.6524304 \\
\hline 4 & 27.74 & 947.072 & 1137.22333 & 106.904369 \\
\hline 5 & 27.73 & 1770.853 & 2116.62733 & 178.669486 \\
\hline 6 & 27.77 & 3777.985 & 4123.015 & 181.755409 \\
\hline 7 & 27.77 & 132.168 & & \\
\hline 8 & 27.79 & 277.252 & & \\
\hline 9 & 27.78 & 562.941 & & \\
\hline 10 & 27.81 & 1147.638 & & 1:32 \\
\hline 11 & 27.78 & 2211.422 & & $1: 16$ \\
\hline 12 & 27.77 & 4196.43 & & 1:8 \\
\hline 13 & 27.79 & 175.511 & & $1: 4$ \\
\hline 14 & 27.81 & 339.183 & & $1: 2$ \\
\hline 15 & 27.82 & 644.953 & & $1: 1$ \\
\hline 16 & 27.82 & 1316.96 & & \\
\hline 17 & 27.77 & 2367.607 & & \\
\hline 18 & 27.75 & 4394.63 & & \\
\hline
\end{tabular}

Compound 3: 3 
Compound 4: 4

\begin{tabular}{|c|c|c|c|c|}
\hline RT & & & Average & SE \\
\hline 1 & 30.45 & 86.071 & 128.807 & 26.3768238 \\
\hline 2 & 30.43 & 174.96 & 258.076333 & 49.9778711 \\
\hline 3 & 30.43 & 370.578 & 483.927 & 63.2016637 \\
\hline 4 & 30.45 & 709.21 & 863.190667 & 83.912099 \\
\hline 5 & 30.44 & 1084.997 & 1253.93433 & 85.0246583 \\
\hline 6 & 30.46 & 1662.62 & 1754.90033 & 46.192503 \\
\hline 7 & 30.48 & 123.39 & & \\
\hline 8 & 30.46 & 251.55 & & \\
\hline 9 & 30.48 & 492.152 & & \\
\hline 10 & 30.5 & 882.378 & & $1: 32$ \\
\hline 1 & 30.47 & 1321.589 & & $1: 16$ \\
\hline 2 & 30.5 & 1797.233 & & 1:8 \\
\hline 3 & 30.49 & 176.96 & & 1:4 \\
\hline 14 & 30.49 & 347.719 & & $1: 2$ \\
\hline 15 & 30.53 & 589.051 & & $1: 1$ \\
\hline 16 & 30.52 & 997.984 & & \\
\hline 17 & 30.5 & 1355.217 & & \\
\hline 18 & 30.46 & 1804.848 & & \\
\hline
\end{tabular}

30.33

30.37

30.38

30.42

30.4

33.14

77.151

$1: 32$

$1: 16$

$1: 8$

$1: 4$

$1: 2$

$1: 1$
10.7958816

2.10428613

$580.537667 \quad 11.8276033$

$1026.61667 \quad 21.092693$

$\begin{array}{rr}24.3606667 & 4.7554791 \\ 67.5233333 & 5.23687522 \\ 155.212667 & 10.7958816 \\ 338.371333 & 2.10428613 \\ 580.537667 & 11.8276033 \\ 1026.61667 & 21.092693 \\ & \\ & \\ & 1: 32 \\ 1: 16 \\ 1: 8 \\ 1: 4 \\ 1: 2 \\ 1: 1 \\ \end{array}$

Compound 5: 5

\begin{tabular}{|c|c|c|c|c|}
\hline RT & & & Average & SE \\
\hline 1 & 31.5 & 956.477 & 1173.16533 & 150.130338 \\
\hline 2 & 31.51 & 1591.165 & 1920.79367 & 201.209096 \\
\hline 3 & 31.5 & 2517.856 & 2970.11667 & 258.582369 \\
\hline 4 & 31.5 & 4084.958 & 4589.83933 & 289.191165 \\
\hline 5 & 31.51 & 5560.397 & 6119.74333 & 282.011897 \\
\hline 6 & 31.54 & 7271.541 & 7562.78567 & 146.655881 \\
\hline 7 & 31.56 & 1101.504 & & \\
\hline 8 & 31.55 & 1885.698 & & \\
\hline
\end{tabular}




\begin{tabular}{|c|c|c|c|c|}
\hline RT & & ea & Average & SE \\
\hline 1 & 33.24 & 96.023 & 129.319 & 19.7835104 \\
\hline 2 & 33.25 & 192.207 & 258.02 & 39.6715652 \\
\hline 3 & 33.25 & 419.59 & 524.258667 & 62.7092584 \\
\hline 4 & 33.25 & 878.821 & 1089.23767 & 114.731274 \\
\hline 5 & 33.23 & 1741.029 & 2120.81867 & 204.543693 \\
\hline 6 & 33.27 & 3723.473 & 4201.32767 & 258.425289 \\
\hline 7 & 33.25 & 127.455 & & \\
\hline 8 & 33.25 & 252.547 & & \\
\hline 9 & 33.27 & 516.754 & & \\
\hline 0 & 33.31 & 1115.178 & & $1: 32$ \\
\hline 1 & 33.27 & 2179.054 & & 1:16 \\
\hline 2 & 33.28 & 4269.691 & & $1: 8$ \\
\hline 3 & 33.31 & 164.479 & & $1: 4$ \\
\hline & 33.28 & 329.306 & & $1: 2$ \\
\hline & 33.32 & 636.432 & & $1: 1$ \\
\hline & 33.29 & 1273.714 & & \\
\hline & 33.29 & 2442.373 & & \\
\hline & 33.27 & 4610.819 & & \\
\hline
\end{tabular}

$1: 32$

$1: 16$

$1: 8$

$1: 4$

$1: 2$

$1: 1$

Compound 6: 6

$\begin{array}{rrr}31.61 & 7738.512 & 1: 8 \\ 31.61 & 1461.515 & 1: 4 \\ 31.59 & 2285.518 & 1: 2 \\ 31.64 & 3413.479 & 1: 1 \\ 31.63 & 5086.648 & \\ 31.61 & 6462.193 & \\ 31.6 & 7678.304 & \end{array}$

Compound 7: 7

\begin{tabular}{|c|c|c|c|c|}
\hline RT & & & Average & SE \\
\hline 1 & 34.38 & 175.064 & 213.947667 & 25.041558 \\
\hline 2 & 34.39 & 295.381 & 362.552667 & 44.4112717 \\
\hline 3 & 34.34 & 454.569 & 551.876667 & 51.2355115 \\
\hline 4 & 34.45 & 708.883 & 801.576667 & 52.1803634 \\
\hline 5 & 34.46 & 953.088 & 1048.42833 & 47.9183056 \\
\hline 6 & 34.34 & 1195.58 & 1189.34367 & 23.7261759 \\
\hline 7 & 34.44 & 206.053 & & \\
\hline 8 & 34.41 & 345.809 & & \\
\hline 9 & 34.44 & 572.716 & & \\
\hline 10 & 34.48 & 806.399 & & $1: 32$ \\
\hline 11 & 34.47 & 1104.534 & & $1: 16$ \\
\hline 12 & 34.49 & 1226.964 & & $1: 8$ \\
\hline 13 & 34.47 & 260.726 & & $1: 4$ \\
\hline 14 & 34.5 & 446.468 & & $1: 2$ \\
\hline 15 & 34.46 & 628.345 & & $1: 1$ \\
\hline 16 & 34.45 & 889.448 & & \\
\hline
\end{tabular}


Compound 8: 8

\begin{tabular}{|c|c|c|c|c|}
\hline RT & & & Average & SE \\
\hline 1 & 39.77 & 270.965 & 337.744333 & 38.7067318 \\
\hline 2 & 39.75 & 529.406 & 577.223333 & 30.385432 \\
\hline 3 & 39.69 & 800.39 & 871.342667 & 37.6318514 \\
\hline 4 & 39.73 & 1040.308 & 1175.58367 & 69.2968947 \\
\hline 5 & 39.74 & 1379.147 & 1408.841 & 15.6636899 \\
\hline 6 & 39.76 & 1620.677 & 1585.29633 & 42.9734785 \\
\hline 7 & 39.75 & 337.222 & & \\
\hline 8 & 39.78 & 568.652 & & \\
\hline 9 & 39.79 & 885.076 & & \\
\hline 10 & 39.84 & 1269.328 & & $1: 32$ \\
\hline 11 & 39.88 & 1415.042 & & $1: 16$ \\
\hline 12 & 39.95 & 1635.439 & & $1: 8$ \\
\hline 13 & 39.84 & 405.046 & & $1: 4$ \\
\hline 14 & 39.84 & 633.612 & & $1: 2$ \\
\hline 15 & 39.87 & 928.562 & & $1: 1$ \\
\hline 16 & 39.87 & 1217.115 & & \\
\hline 17 & 39.82 & 1432.334 & & \\
\hline 18 & 39.89 & 1499.773 & & \\
\hline
\end{tabular}

Compound 9: 9

\begin{tabular}{rrrrr} 
RT & \multicolumn{2}{c}{ Area } & \multicolumn{2}{l}{ Average } \\
1 & 45.61 & 10.928 & 17.314 & 4.99804452 \\
2 & 45.57 & 52.688 & 76.0756667 & 14.0772188 \\
3 & 45.59 & 178.969 & 235.629 & 30.2933294 \\
4 & 45.58 & 500.531 & 610.220333 & 57.0872892 \\
5 & 45.56 & 1193.708 & 1328.207 & 67.2519709 \\
6 & 45.59 & 2561.491 & 2565.985 & 117.567103 \\
7 & 45.63 & 13.847 & & \\
8 & 45.65 & 74.195 & & \\
9 & 45.69 & 245.377 & & \\
10 & 45.69 & 637.623 & & $1: 32$ \\
11 & 45.64 & 1394.458 & & $1: 16$ \\
12 & 45.7 & 2771.827 & & $1: 8$ \\
13 & 45.7 & 27.167 & & $1: 4$ \\
14 & 45.72 & 101.344 & & $1: 2$ \\
15 & 45.7 & 282.541 & & $1: 1$ \\
16 & 45.73 & 692.507 & & \\
17 & 45.7 & 1396.455 & & \\
18 & 45.68 & 2364.637 & &
\end{tabular}

Compound 10: 10

\begin{tabular}{|c|c|c|c|c|}
\hline RT & & & Average & SE \\
\hline 1 & 45.59 & 303.754 & 406.297 & 64.7972065 \\
\hline 2 & 45.61 & 667.608 & 794.941333 & 74.72893 \\
\hline
\end{tabular}




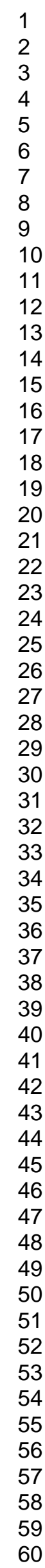

$\begin{array}{rrrrl}3 & 45.53 & 1267.042 & 1401.47833 & 71.8207116 \\ 4 & 45.56 & 2115.33 & 2288.70633 & 87.4285358 \\ 5 & 45.6 & 2842.208 & 3006.536 & 86.5003693 \\ 6 & 45.69 & 3884.895 & 3709.23267 & 125.503549 \\ 7 & 45.65 & 388.941 & & \\ 8 & 45.65 & 790.837 & & \\ 9 & 45.67 & 1424.881 & 1: 32 \\ 10 & 45.71 & 2355.729 & 1: 16 \\ 11 & 45.66 & 3135.542 & 1: 8 \\ 12 & 45.67 & 3776.677 & 1: 4 \\ 13 & 45.72 & 526.196 & 1: 2 \\ 14 & 45.72 & 926.379 & \\ 15 & 45.7 & 1512.512 & \\ 16 & 45.69 & 2395.06 & & \\ 17 & 45.68 & 3041.858 & & \\ 18 & 45.62 & 3466.126 & & \end{array}$




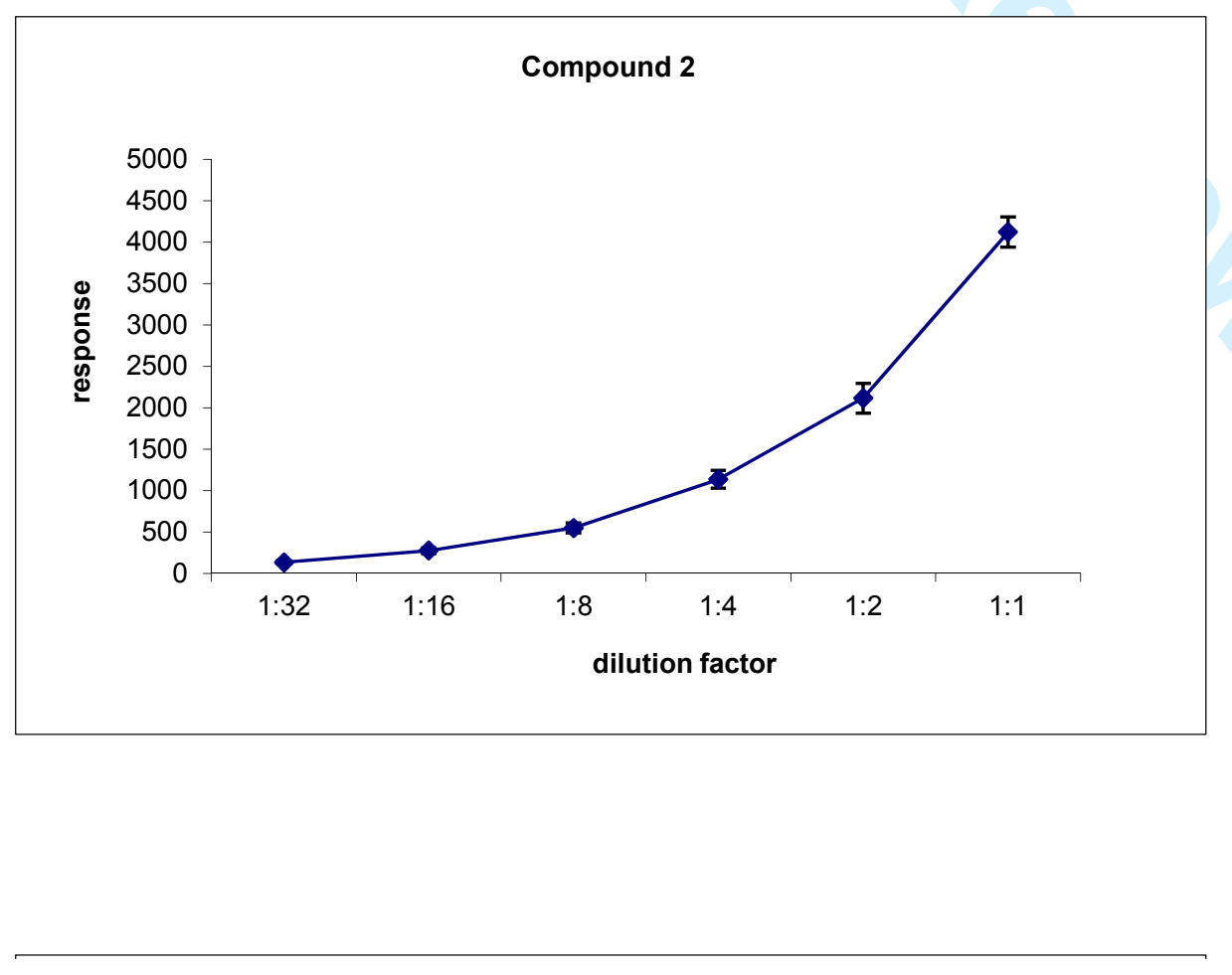




\section{Page 51 of 80}

1

2

3

4

5

6

7

8

9

10

11

12

13

14

15

16

17

18

19

20

21

22

23

24

25

26

27

28

29

30

31

32

33

34

35

36

37

38

39

40

41

42

43

44

45

46

47

48

49

50

51

52

53

54

55

56

57

58

59

60
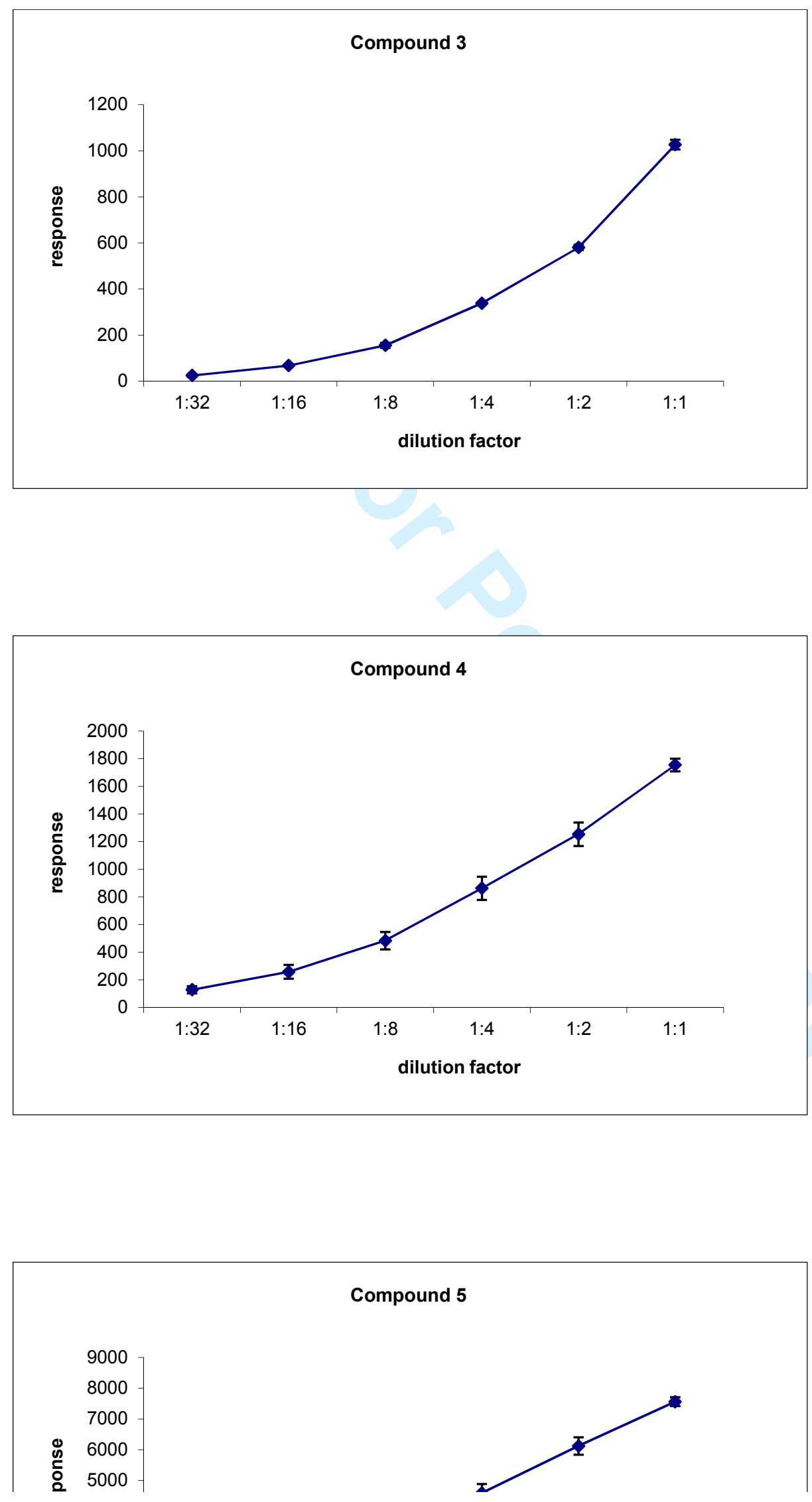

Springer 

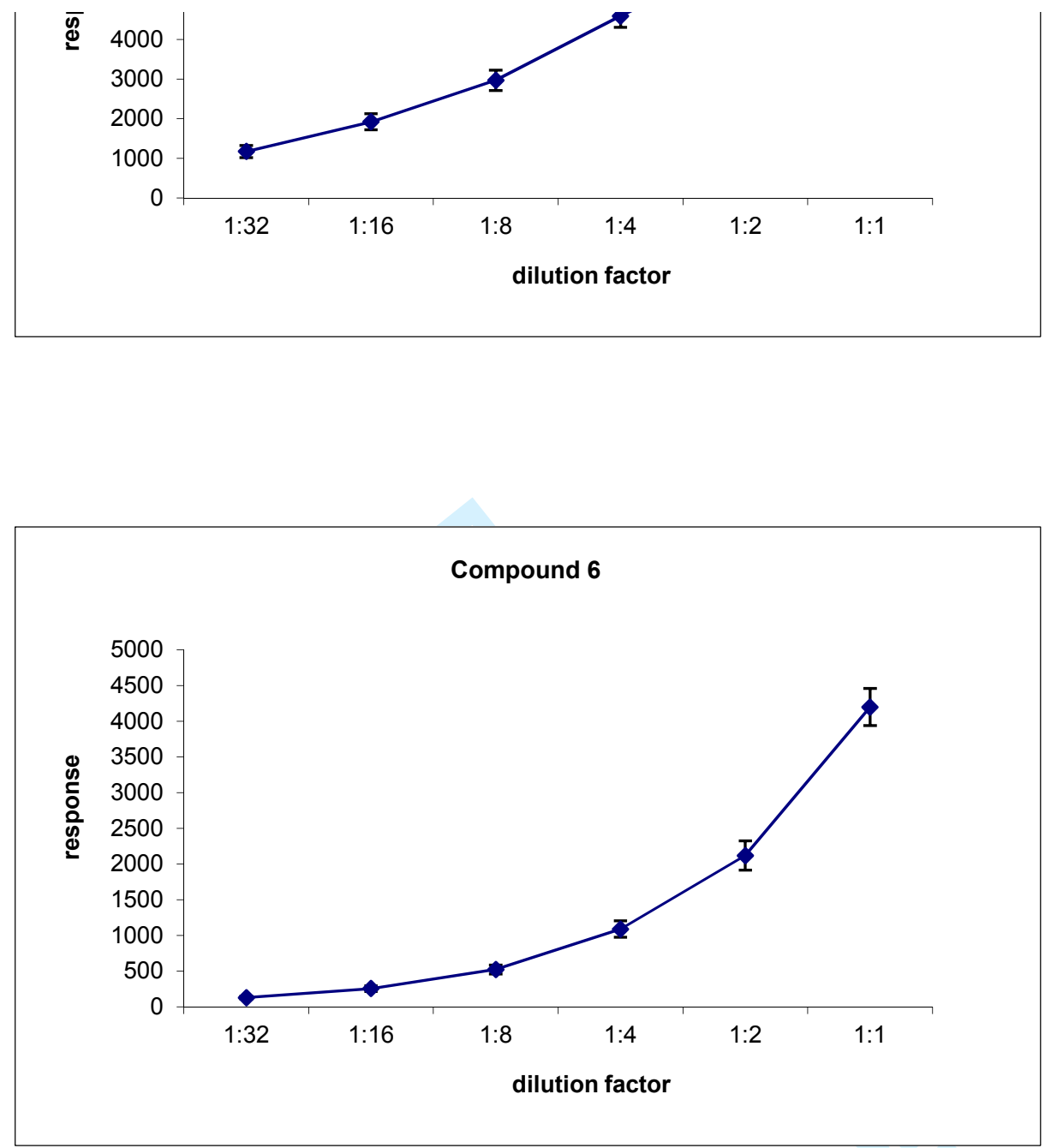

36

37

38

39

40

41

42

43

44

45

46

47

48

49

50

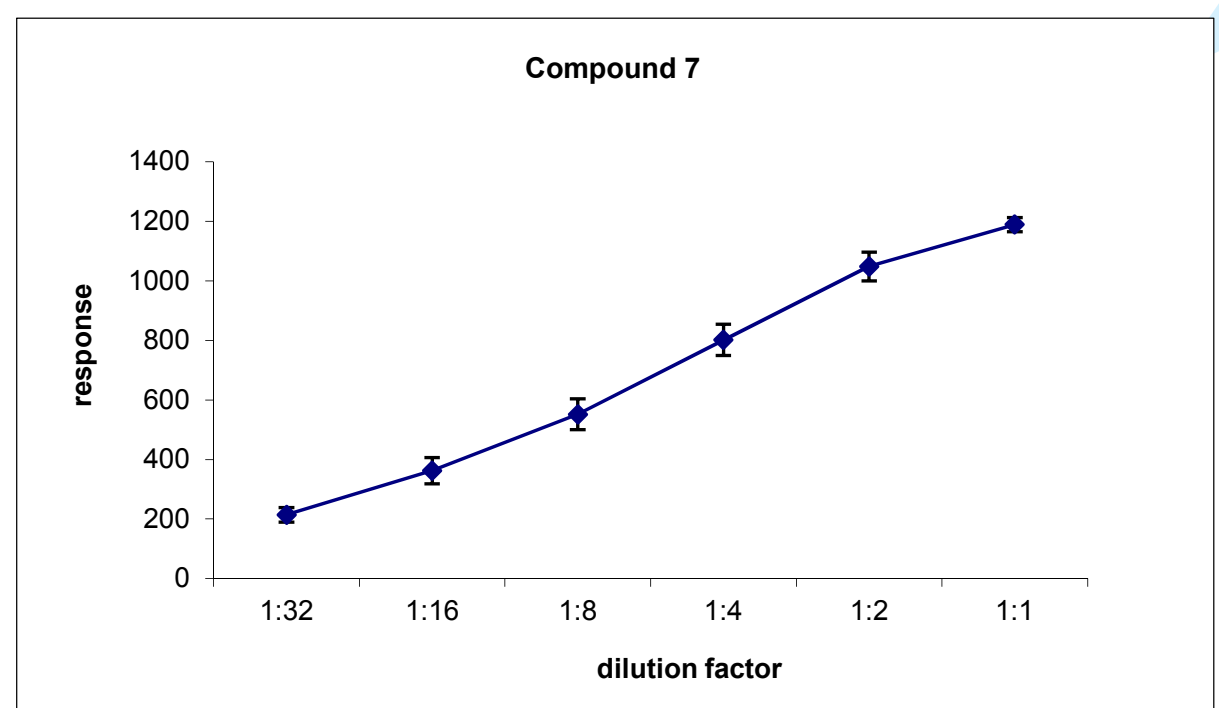


2

3

4

5

6

7

8

9

10

11

12

13

14

15

16

17

18

19

20

21

22

23

24

25

26

27

28

29

30

31

32

33

34

35

36

37

38

39

40

41

42

43

44

45

46

47

48

49

50

51

52

53

54

55

56

57

58

59

60
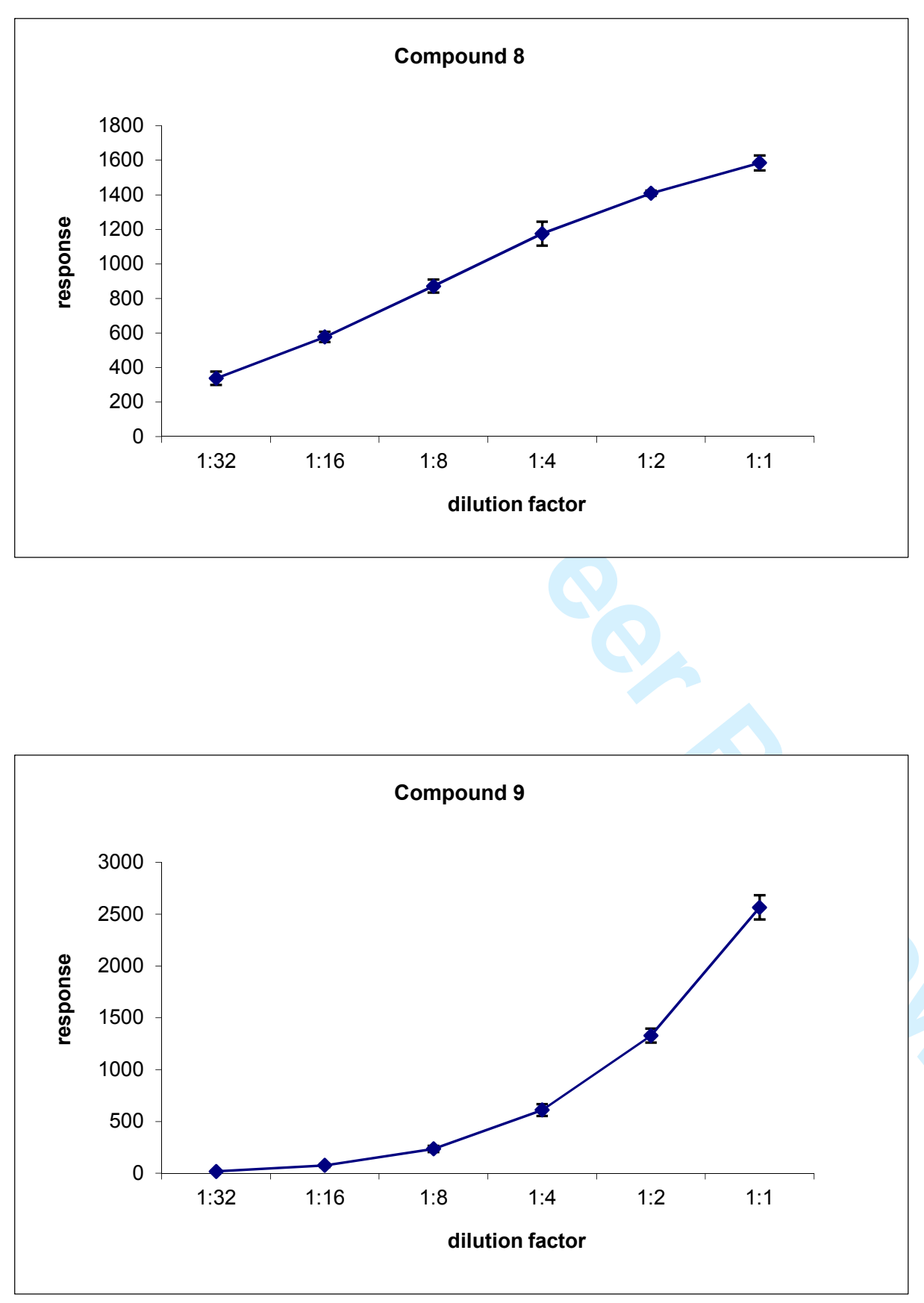

Compound 10 


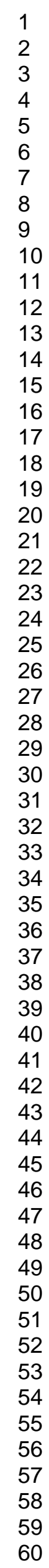

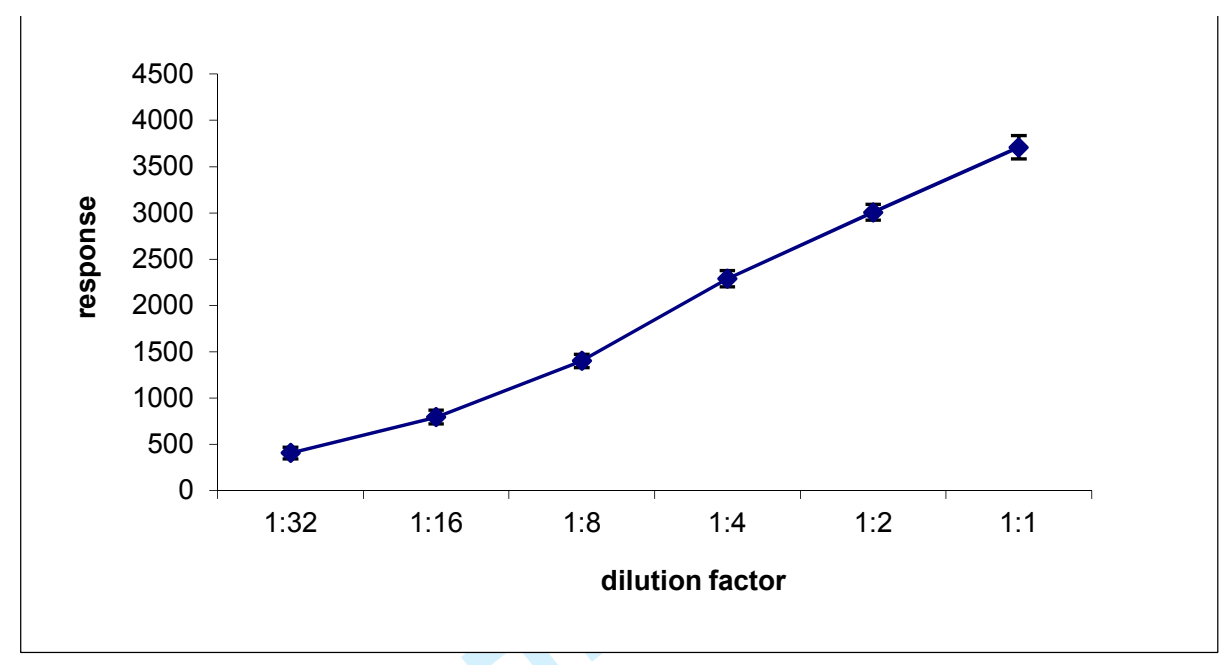

20

1 
Supplementary Data 3.

Assessment of linearity - Cleopatra mandarin

Compound 1: 1

\begin{tabular}{|c|c|c|c|c|}
\hline RT & & ea & Average & SE \\
\hline 1 & 10.96 & 17.373 & 55.0126667 & 27.8433511 \\
\hline 2 & 10.91 & 52.319 & 86.1523333 & 22.3578713 \\
\hline 3 & 10.89 & 131.107 & 250.748667 & 94.2939156 \\
\hline 4 & 10.88 & 368.479 & 641.227333 & 238.782756 \\
\hline 5 & 10.85 & 807.574 & 1264.95 & 466.874492 \\
\hline 6 & 10.85 & 3100.715 & 3326.17367 & 192.540501 \\
\hline 7 & 10.88 & 38.291 & & \\
\hline 8 & 10.89 & 77.749 & & \\
\hline 9 & 10.89 & 184.322 & & \\
\hline 10 & 10.89 & 438.105 & & $1: 32$ \\
\hline 11 & 10.87 & 788.641 & & $1: 16$ \\
\hline 12 & 10.87 & 3168.548 & & $1: 8$ \\
\hline 13 & 10.86 & 109.374 & & $1: 4$ \\
\hline 14 & 10.81 & 128.389 & & $1: 2$ \\
\hline 15 & 10.85 & 436.817 & & $1: 1$ \\
\hline 16 & 10.9 & 1117.098 & & \\
\hline 17 & 10.9 & 2198.635 & & \\
\hline 18 & 10.9 & 3709.258 & & \\
\hline
\end{tabular}

Compound 2: 2

\begin{tabular}{|c|c|c|c|c|}
\hline RT & & & Average & SE \\
\hline 1 & 14.11 & 36.029 & 64.9596667 & 18.3340914 \\
\hline 2 & 14.06 & 82.932 & 138.579667 & 34.9301086 \\
\hline 3 & 14.03 & 200.656 & 315.746 & 78.5363106 \\
\hline 4 & 14.01 & 496.192 & 670.704667 & 118.453473 \\
\hline 5 & 14 & 967.084 & 1274.06633 & 179.79963 \\
\hline 6 & 14.01 & 1932.176 & 2272.218 & 188.48083 \\
\hline 7 & 14.04 & 59.914 & & \\
\hline 8 & 14.04 & 129.827 & & \\
\hline 9 & 14.06 & 280.719 & & \\
\hline 10 & 14.03 & 619.207 & & $1: 32$ \\
\hline 11 & 14.05 & 1265.369 & & $1: 16$ \\
\hline 12 & 14.05 & 2301.336 & & $1: 8$ \\
\hline 13 & 14.04 & 98.936 & & $1: 4$ \\
\hline 14 & 14.03 & 202.98 & & $1: 2$ \\
\hline 15 & 14.03 & 465.863 & & $1: 1$ \\
\hline 16 & 14.07 & 896.715 & & \\
\hline 17 & 14.07 & 1589.746 & & \\
\hline 18 & 14.08 & 2583.142 & & \\
\hline
\end{tabular}

Compound 3: 3
RT 18.15
Area Average SE $10.156 \quad 21.7116667 \quad 7.1406496$ 
Compound 4: 4

\begin{tabular}{|c|c|c|c|c|}
\hline RT & \multicolumn{2}{|c|}{ Area } & Average & SE \\
\hline 1 & 21.61 & 61.54 & 92.9036667 & 20.9722831 \\
\hline 2 & 21.6 & 122.389 & 172.781667 & 31.1673775 \\
\hline 3 & 21.58 & 245.081 & 340.497333 & 64.6455549 \\
\hline 4 & 21.54 & 515.044 & 644.553 & 90.0481082 \\
\hline 5 & 21.56 & 941.605 & 1125.207 & 111.604444 \\
\hline 6 & 21.6 & 1644.877 & 1825.99833 & 100.262206 \\
\hline 7 & 21.59 & 84.466 & & \\
\hline 8 & 21.59 & 166.203 & & \\
\hline 9 & 21.58 & 312.648 & & \\
\hline 10 & 21.59 & 600.926 & & $1: 32$ \\
\hline 11 & 21.58 & 1107.079 & & $1: 16$ \\
\hline 12 & 21.59 & 1842.035 & & $1: 8$ \\
\hline 13 & 21.6 & 132.705 & & $1: 4$ \\
\hline 14 & 21.58 & 229.753 & & $1: 2$ \\
\hline 15 & 21.6 & 463.763 & & 1:1 \\
\hline 16 & 21.6 & 817.689 & & \\
\hline 17 & 21.61 & 1326.937 & & \\
\hline 18 & 21.61 & 1991.083 & & \\
\hline
\end{tabular}

$\begin{array}{rrl}28.824 & 50.355 & 13.5393135 \\ 84.567 & 127.008333 & 30.3858719 \\ 202.599 & 272.267333 & 46.0991345 \\ 408.5 & 489.517333 & 46.3460039 \\ 712.28 & 781.168333 & 39.1106885 \\ 20.222 & & \\ 46.899 & \\ 110.56 & 1: 32 \\ 254.803 & 1: 16 \\ 491.026 & 1: 8 \\ 783.523 & 1: 4 \\ 34.757 & 1: 2 \\ 75.342 & 1: 1 \\ 185.898 & \\ 359.4 & \end{array}$

Compound 5: 5

\begin{tabular}{lrrrr} 
RT & \multicolumn{2}{c}{ Area } & \multicolumn{2}{c}{ Average } \\
1 & 25.91 & 178.066 & 248.334 & 51.2068075 \\
2 & 25.91 & 313.709 & 423.47 & 69.900961 \\
3 & 25.89 & 600.628 & 793.845333 & 130.28155 \\
4 & 25.86 & 1085.974 & 1363.017 & 184.493618 \\
5 & 25.9 & 1780.339 & 2150.107 & 216.731482 \\
6 & 25.92 & 2853.27 & 3202.81167 & 192.472331 \\
7 & 25.9 & 218.945 & & \\
8 & 25.91 & 403.365 & & \\
9 & 25.92 & 739.06 & &
\end{tabular}




$\begin{array}{lrrl}10 & 25.95 & 1290.472 & 1: 32 \\ 11 & 25.9 & 2139.105 & 1: 16 \\ 12 & 25.92 & 3237.932 & 1: 8 \\ 13 & 25.93 & 347.991 & 1: 4 \\ 14 & 25.92 & 553.336 & 1: 2 \\ 15 & 25.91 & 1041.848 & 1: 1 \\ 16 & 25.94 & 1712.605 & \\ 17 & 25.95 & 2530.877 & \\ 18 & 25.97 & 3517.233 & \end{array}$

Compound 6: 6

\begin{tabular}{|c|c|c|c|c|}
\hline RT & & & Average & SE \\
\hline 1 & 30.5 & 118.64 & 183.678667 & 43.2363313 \\
\hline 2 & 30.5 & 222.359 & 314.874667 & 58.272492 \\
\hline 3 & 30.48 & 396.304 & 559.770667 & 105.121709 \\
\hline 4 & 30.46 & 710.403 & 903.469667 & 127.662674 \\
\hline 5 & 30.51 & 1068.198 & 1288.66633 & 130.248764 \\
\hline 6 & 30.44 & 1435.684 & 1676.92867 & 132.164942 \\
\hline 7 & 30.49 & 166.846 & & \\
\hline 8 & 30.47 & 299.751 & & \\
\hline 9 & 30.47 & 527.002 & & \\
\hline 10 & 30.48 & 855.306 & & $1: 32$ \\
\hline 11 & 30.45 & 1278.736 & & $1: 16$ \\
\hline 12 & 30.47 & 1703.991 & & $1: 8$ \\
\hline 13 & 30.48 & 265.55 & & $1: 4$ \\
\hline 14 & 30.46 & 422.514 & & $1: 2$ \\
\hline 15 & 30.45 & 756.006 & & $1: 1$ \\
\hline 16 & 30.48 & 1144.7 & & \\
\hline 17 & 30.47 & 1519.065 & & \\
\hline 18 & 30.46 & 1891.111 & & \\
\hline
\end{tabular}

Compound 7: 7

\begin{tabular}{rrrrr} 
& \multicolumn{2}{c}{ RT } & \multicolumn{2}{c}{ Average } \\
1 & 32.03 & 8.749 & 14.15 & 3.62768618 \\
2 & 32.04 & 22.188 & 30.137 & 4.87367284 \\
3 & 32 & 57.347 & 78.005 & 13.843338 \\
4 & 31.98 & 138.474 & 179.87 & 26.841396 \\
5 & 32.03 & 318.916 & 390.742 & 39.6826991 \\
6 & 32.01 & 724.873 & 776.961333 & 27.3343091 \\
7 & 32.02 & 12.655 & & \\
8 & 32.01 & 29.226 & & \\
9 & 32 & 72.37 & & \\
10 & 32.01 & 170.968 & $1: 32$ \\
11 & 32.01 & 397.416 & $1: 16$ \\
12 & 32.01 & 788.632 & $1: 8$ \\
13 & 32.02 & 21.046 & $1: 4$ \\
14 & 31.99 & 38.997 & $1: 2$ \\
15 & 32.01 & 104.298 & \\
16 & 32.04 & 230.168 & & \\
17 & 32.04 & 455.894 & &
\end{tabular}


$\begin{array}{lll}18 & 32.04 & 817.379\end{array}$

Compound 8: 8

\begin{tabular}{rrrrl} 
& RT & \multicolumn{2}{c}{ Area } & \multicolumn{2}{l}{ Average } & SE \\
1 & 32.56 & 420.83 & 686.180667 & 161.440909 \\
2 & 32.56 & 877.118 & 1240.73633 & 218.671648 \\
3 & 32.55 & 1698.738 & 2409.663 & 435.238112 \\
4 & 32.54 & 3411.708 & 4276.24133 & 548.842789 \\
5 & 32.58 & 5997.775 & 6919.35033 & 491.022785 \\
6 & 32.56 & 8910.636 & 9421.076 & 275.450367 \\
7 & 32.57 & 659.541 & & \\
8 & 32.55 & 1212.098 & & \\
9 & 32.57 & 2330.113 & & \\
10 & 32.57 & 4122.742 & & $1: 32$ \\
11 & 32.57 & 7086.311 & & $1: 16$ \\
12 & 32.57 & 9496.833 & & $1: 8$ \\
13 & 32.57 & 978.171 & & $1: 4$ \\
14 & 32.57 & 1632.993 & $1: 2$ \\
15 & 32.57 & 3200.138 & \\
16 & 32.6 & 5294.274 & & $1: 1$ \\
17 & 32.6 & 7673.965 & & \\
18 & 32.62 & 9855.759 & &
\end{tabular}

Compound 9: 9

\begin{tabular}{rrrrr} 
& \multicolumn{2}{c}{ RT } & \multicolumn{2}{c}{ Average } \\
1 & 33.29 & 47.365 & 79.069 & 20.1199092 \\
2 & 33.29 & 107.984 & 155.955 & 30.4653154 \\
3 & 33.29 & 224.859 & 322.539333 & 63.7615052 \\
4 & 33.26 & 503.942 & 669.413 & 109.916221 \\
5 & 33.31 & 1021.23 & 1257.58667 & 139.54641 \\
6 & 33.27 & 2080.345 & 2329.66867 & 140.176003 \\
7 & 33.27 & 73.46 & & \\
8 & 33.27 & 147.406 & & \\
9 & 33.28 & 300.383 & & \\
10 & 33.26 & 626.812 & $1: 32$ \\
11 & 33.26 & 1247.23 & $1: 16$ \\
12 & 33.26 & 2343.307 & $1: 8$ \\
13 & 33.28 & 116.382 & $1: 4$ \\
14 & 33.25 & 212.475 & $1: 2$ \\
15 & 33.26 & 442.376 & & $1: 1$ \\
16 & 33.28 & 877.485 & & \\
17 & 33.29 & 1504.3 & & \\
18 & 33.29 & 2565.354 & &
\end{tabular}

Compound 10: 10

\begin{tabular}{|c|c|c|c|c|}
\hline RT & & & Average & SE \\
\hline 1 & 34.08 & 365.848 & 486.474 & 90.1885766 \\
\hline 2 & 34.07 & 627.232 & 801.929667 & 123.902739 \\
\hline 3 & 34.06 & 1066.674 & 1413.38867 & 234.768978 \\
\hline
\end{tabular}




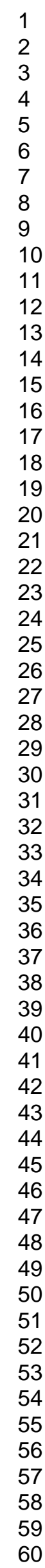

$\begin{array}{rrrrl}4 & 34.04 & 1874.965 & 2350.174 & 302.737221 \\ 5 & 34.09 & 3027.766 & 3613.29633 & 336.200904 \\ 6 & 34.07 & 4664.396 & 5242.97833 & 314.015893 \\ 7 & 34.08 & 430.645 & & \\ 8 & 34.06 & 737.074 & & \\ 9 & 34.08 & 1312.536 & 1: 32 \\ 10 & 34.06 & 2262.845 & 1: 16 \\ 11 & 34.07 & 3619.777 & 1: 8 \\ 12 & 34.09 & 5320.728 & 1: 4 \\ 13 & 34.06 & 662.929 & 1: 2 \\ 14 & 34.05 & 1041.483 & 1: 1 \\ 15 & 34.08 & 1860.956 & \\ 16 & 34.1 & 2912.712 & \\ 17 & 34.1 & 4192.346 & \end{array}$



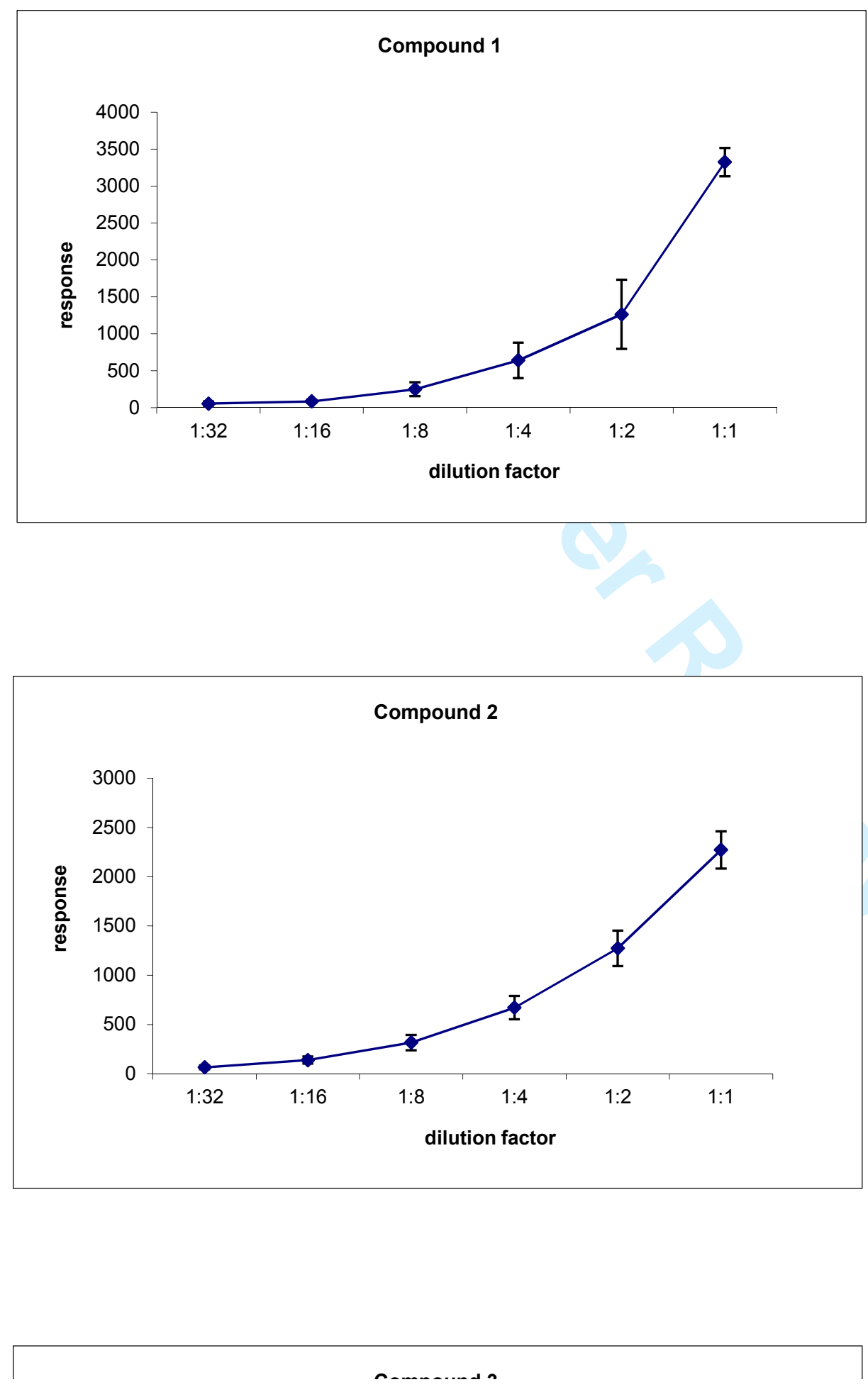


1
2
3
4
5
6
7
8
9
10
11
12
13
14
15
16
17
18
19
20
21
22
23
24
25
26
27
28
29
30
31
32
33
34
35
36
37
38
39
40
41
42
43
44
45
46
47
48
49
50
51
52
53
54
55
56
57
58
60
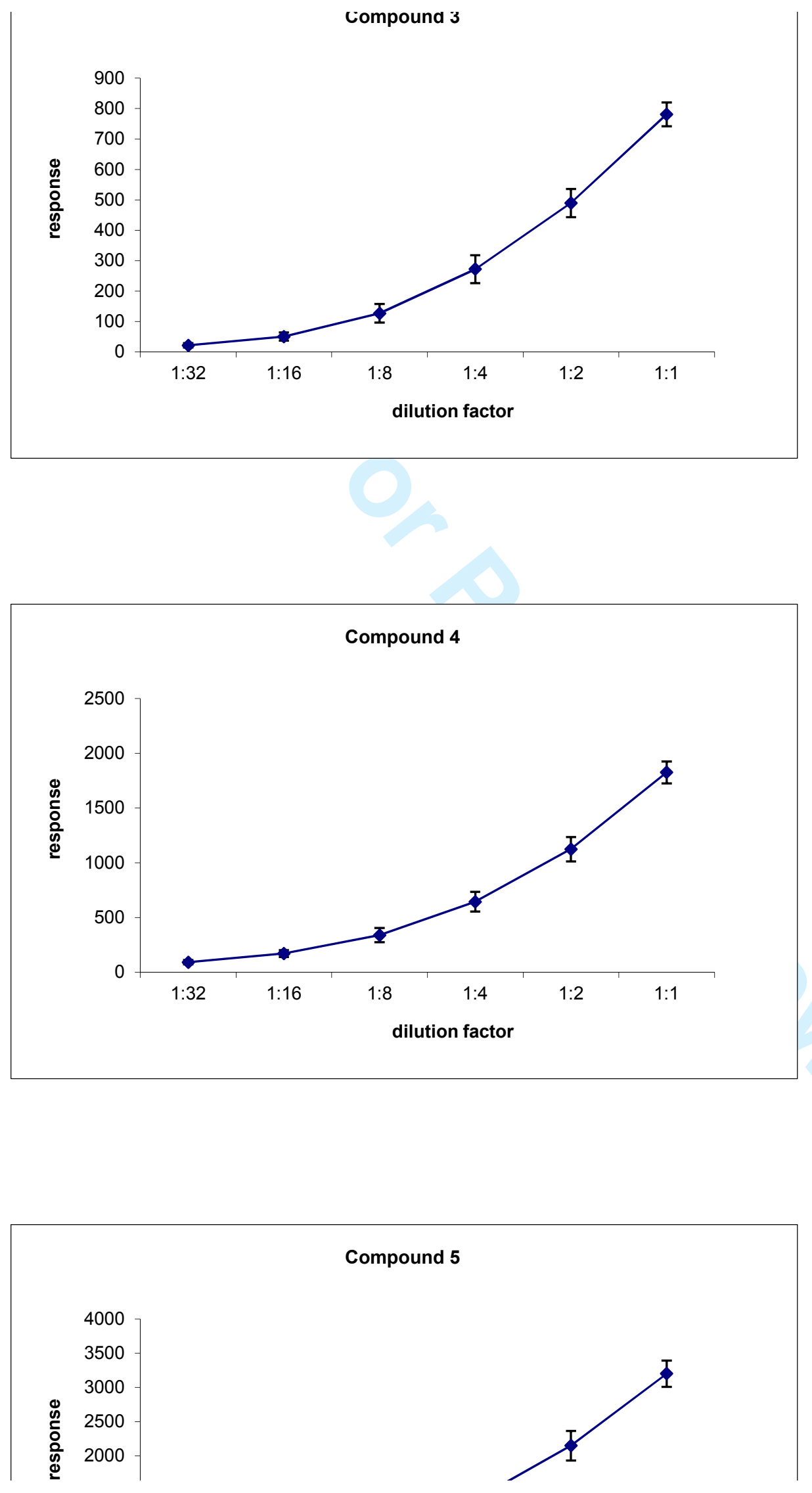

Springer 

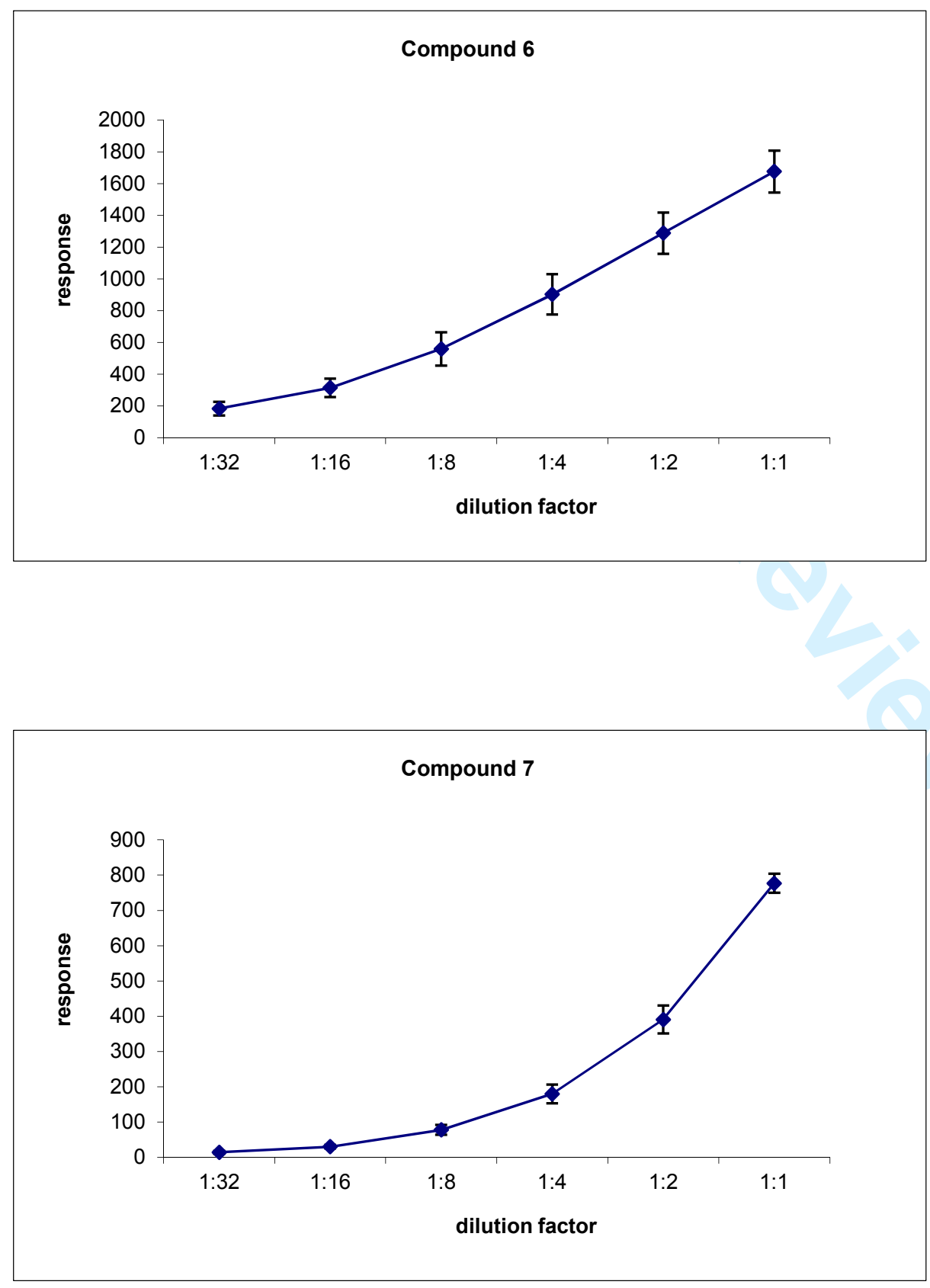
1

2

3

4

5

6

7

8

9

10

11

12

13

14

15

16

17

18

19

20

21

22

23

24

25

26

27

28

29

30

31

32

33

34

35

36

37

38

39

40

41

42

43

44

45

46

47

48

49

50

51

52

53

54

55

56

57

58

59

60
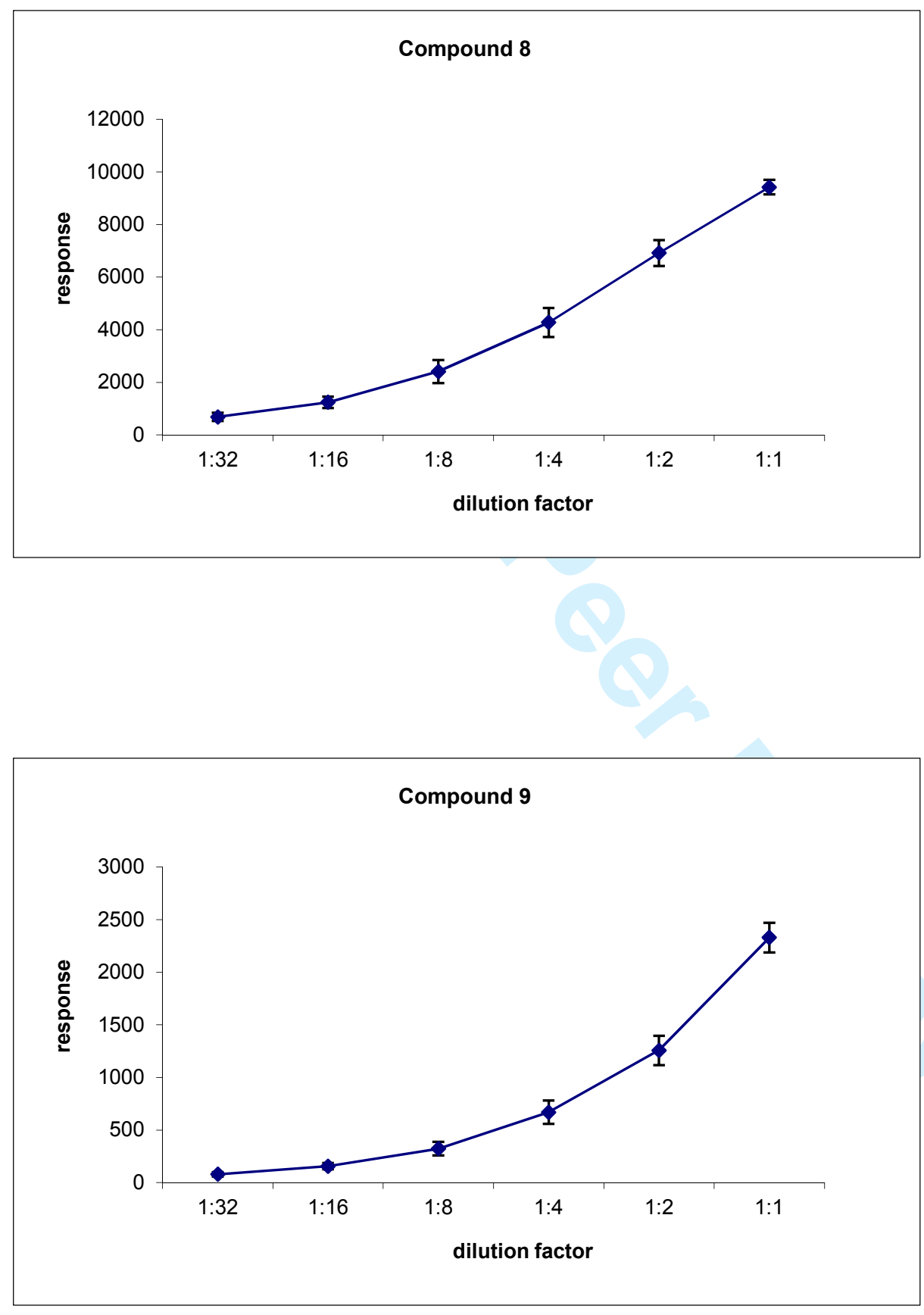

Compound 10

Springer 


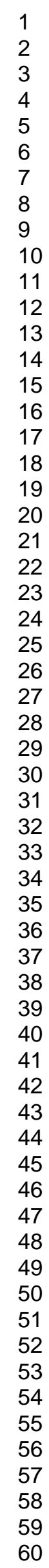

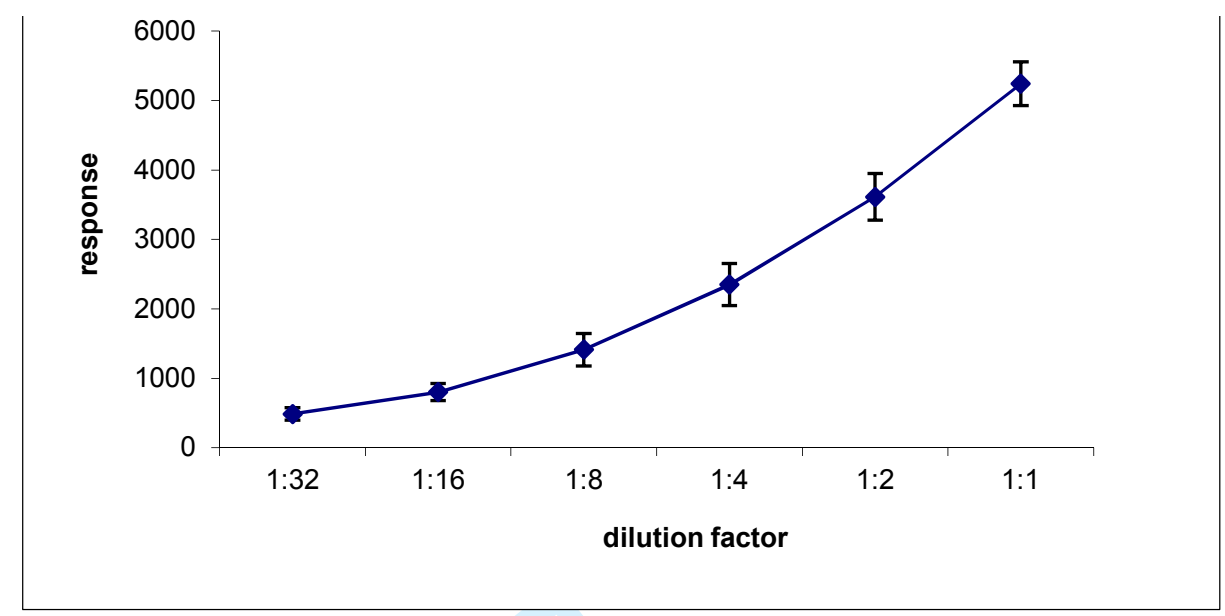


a)
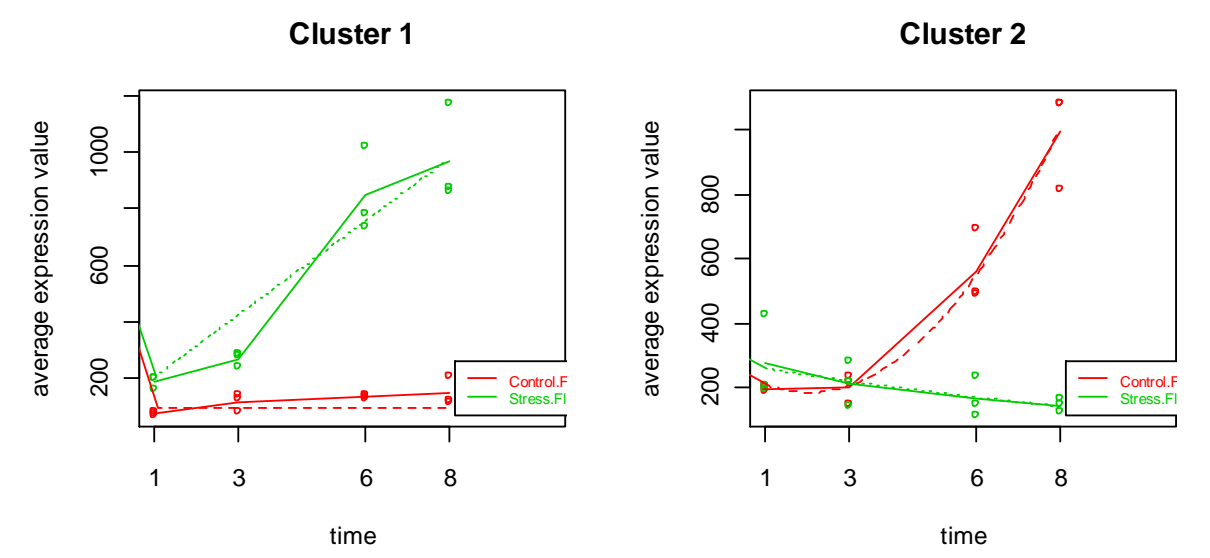

Median profile of 60 mass chromatographic features

Median profile of 86 mass chromatographic features

Cluster 3

Cluster 4
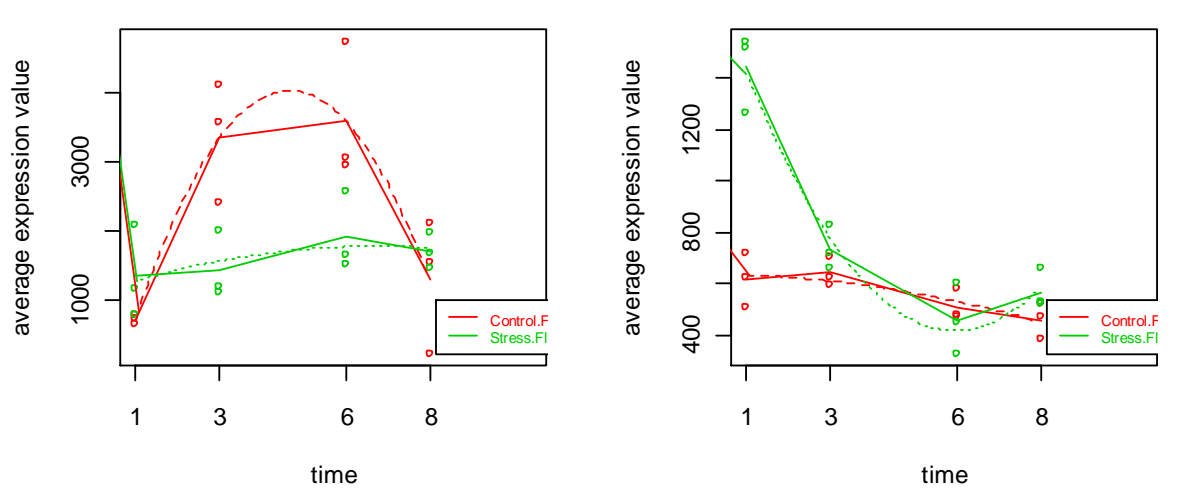

b)

Median profile of 41 mass chromatographic features

Median profile of 34 mass chromatographic features

Cluster 1
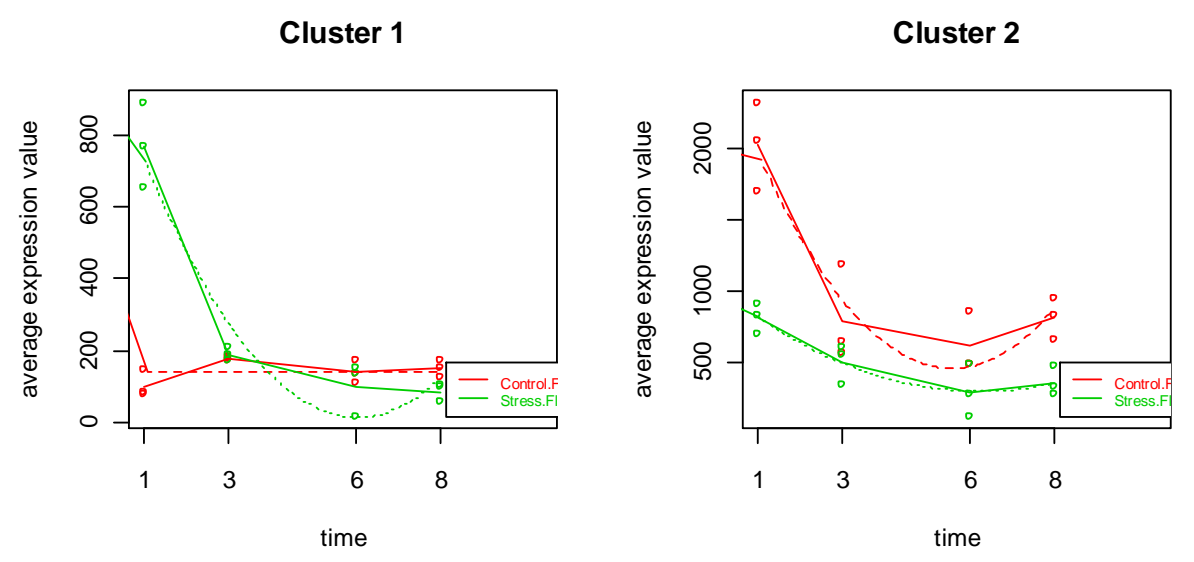

Median profile of 103 mass chromatographic features

Median profile of 64 mass chromatographic features

Cluster 3

Cluster 4
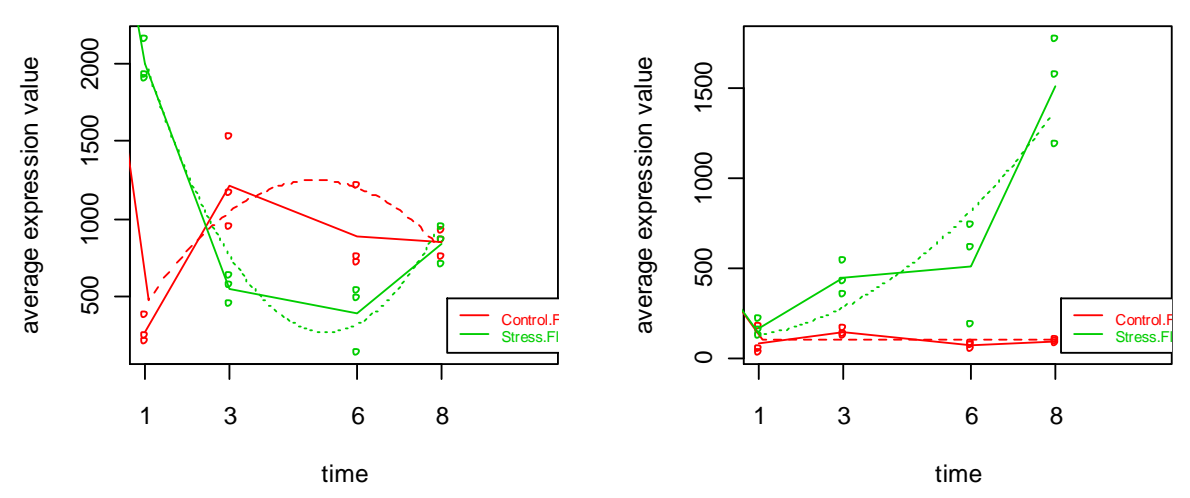

Median profile of 55 mass chromatographic features

Supplementary Figure 4. Differential metabolite profiles in Carrizo citrange (a) and Cleopatra mandarin (b) subjected to soil flooding stress. 
a)
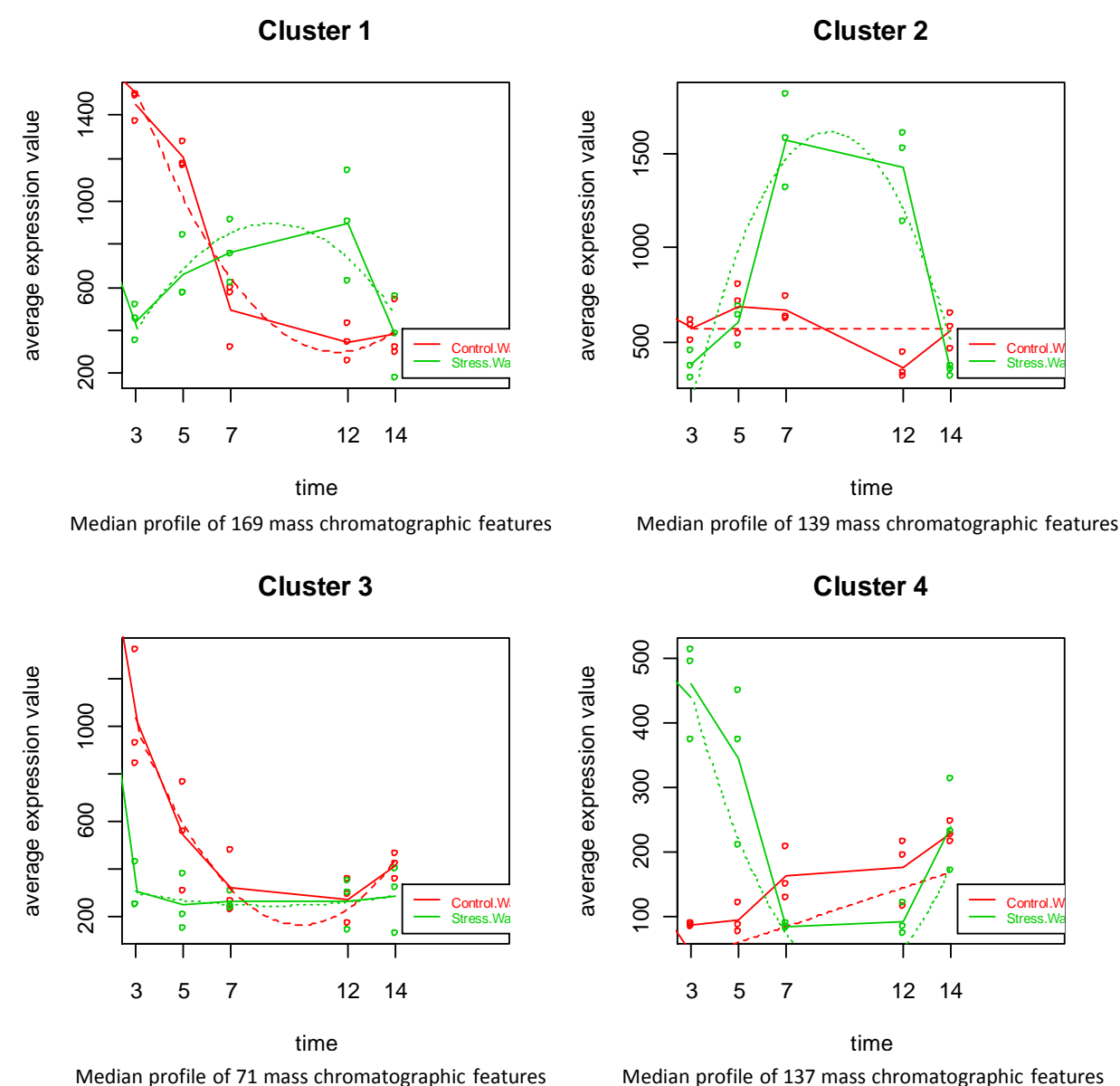

b)
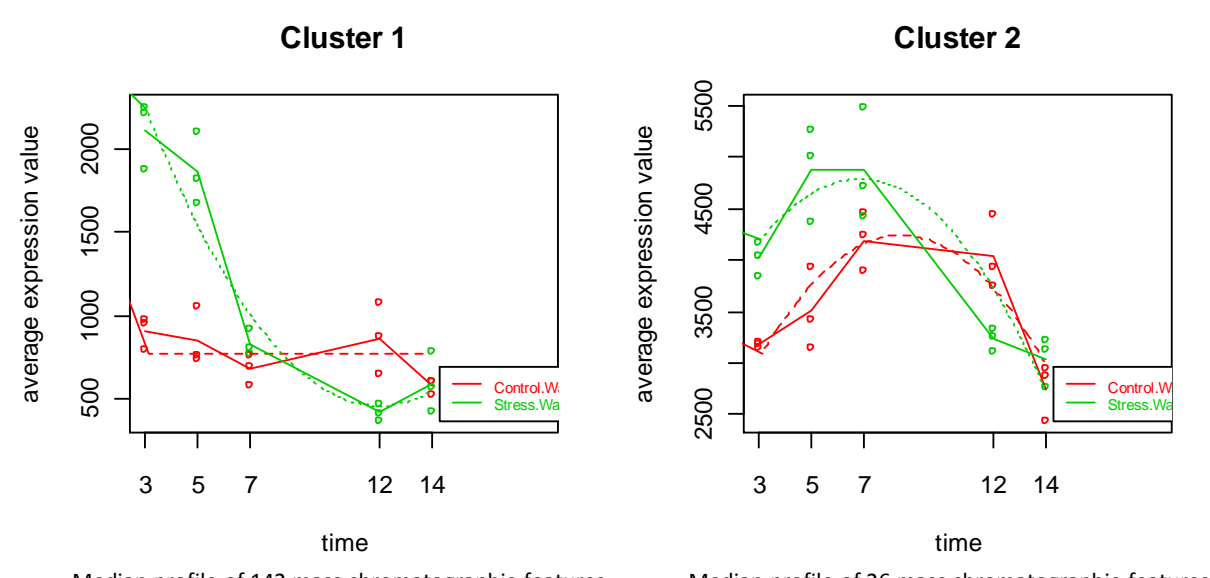

Median profile of 142 mass chromatographic features

Median profile of 26 mass chromatographic features

Cluster 3

Cluster 4
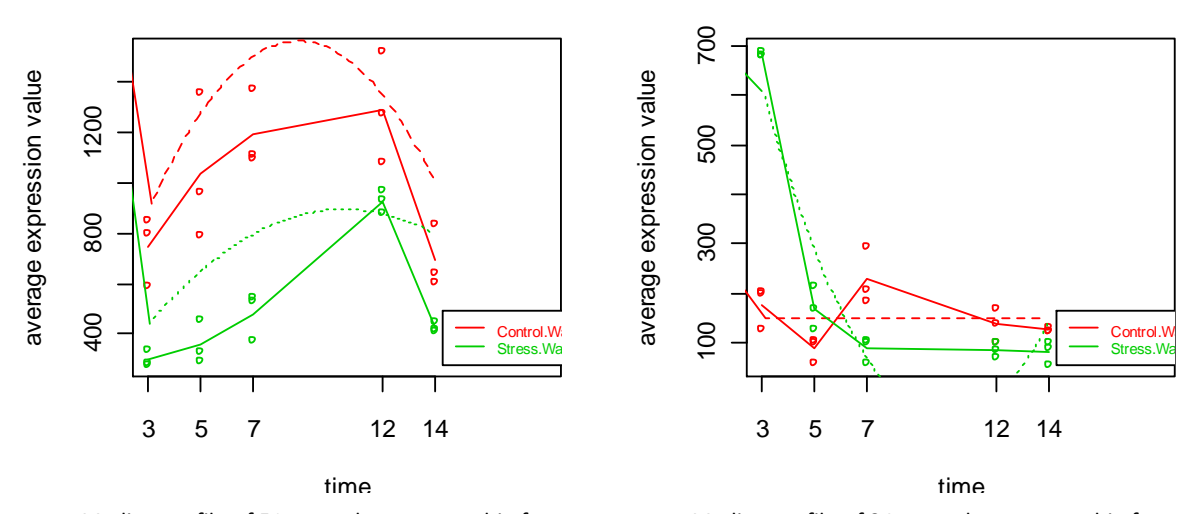

Median profile of 34 mass chromatographic features

Supplementary Figure 5. Differential metabolite profiles in Carrizo citrange (a) and Cleopatra mandarin (b) subjected to drought. 


\section{Supplementary Data 6.}

\section{Mass chromatographic features with area values 1}

\begin{tabular}{|c|c|c|c|}
\hline & & & \\
\hline $5.22672 \mathrm{E}-09$ & 313.1468788 & 2069.7921 & \\
\hline $1.63758 \mathrm{E}-12$ & 314.1486646 & 2069.682219 & {$[1][\mathrm{M}]+$} \\
\hline $6.15286 \mathrm{E}-13$ & 315.1524121 & 2069.394021 & {$[1][M+1]+$} \\
\hline $8.54393 E-09$ & \begin{tabular}{|l|}
376.1570781 \\
\end{tabular} & 2069.478569 & [2][M]+ \\
\hline $5.98201 \mathrm{E}-08$ & 377.1626572 & 2068.444197 & {$[2][M+1]+$} \\
\hline $4.20722 \mathrm{E}-07$ & \begin{tabular}{|l|}
625.2862184 \\
\end{tabular} & 2068.075967 & [3][M]+ \\
\hline $4.15608 \mathrm{E}-05$ & 626.2880626 & 2069.17181 & {$[3][M+1]+$} \\
\hline $9.25926 \mathrm{E}-14$ & 6001 & 2390.3 & {$[14][M]+$} \\
\hline 2.22045E-16 & 329.1655653 & 2389.740845 & {$[14][M+1]+$} \\
\hline $3.9968 \mathrm{E}-15$ & 330.1 & 2388.720517 & {$[14][M+2]+$} \\
\hline-16 & 368 & 2389. & {$[15][\mathrm{M}]+$} \\
\hline 0 & 369.1968911 & 2388.923696 & {$[15][M+1]+$} \\
\hline 3.75226E-08 & 390. & 2390.1 & {$[16][\mathrm{M}]+$} \\
\hline & 192 & 238 & $+1]+$ \\
\hline $4.37029 \mathrm{E}-07$ & 653.3185227 & 2388.720517 & M]+ \\
\hline $1.06162 \mathrm{E}-06$ & 654.322455 & 2388.720517 & {$[17][M+1]+$} \\
\hline 168 & 26 & $\overline{64}$ & $\overline{\mathrm{V}]+}$ \\
\hline 818132 & 261. & 1826.586169 & {$[21][M+1]+$} \\
\hline 577808 & 300 & 1826. & [22][M]+ \\
\hline 15 & 741 & & $+1]+$ \\
\hline & & & {$[27][M]+$} \\
\hline 569 & 381.2 & $2742.4 \varepsilon$ & {$[28][\mathrm{M}]+$} \\
\hline 0 & 382 & 2741.8 & {$[28][\mathrm{M}+1]+$} \\
\hline $3.4861 \mathrm{E}-14$ & 54 & 274 & {$[27]$} \\
\hline 2.06744E-09 & 444.2219434 & 2741.7 & \\
\hline $2.22045 \mathrm{E}-16$ & 94 & 274 & {$[28][M+2]+$} \\
\hline$=-10$ & 94 & 267 & \\
\hline 12 & 315. & 274 & [27] \\
\hline $605 \mathrm{E}-10$ & 41 & 27 & \\
\hline 0 & 737 & 506 & \\
\hline 44 & 258. & 292 & \\
\hline $89 \mathrm{E}-06$ & 403.1 & 2741. & \\
\hline $5.99978 \mathrm{E}-05$ & 278.6200148 & 2741.4 & \\
\hline $2.37232 \mathrm{E}-12$ & 384.2 & 2740.9 & {$[28][\mathrm{M}+3]+$} \\
\hline $1.67875 \mathrm{E}-06$ & 308.1683092 & 1671.505414 & {$[48][\mathrm{M}]+$} \\
\hline $1.80416 \mathrm{E}-07$ & 249 & 1671. & [49][M]+ \\
\hline $55 \mathrm{E}-06$ & 348. & 3638 & {$[50][\mathrm{M}]+$} \\
\hline $8.80162 \mathrm{E}-07$ & 309.1746102 & 1671.458475 & {$[48][M+1]+$} \\
\hline $1.41902 \mathrm{E}-08$ & 327.1827762 & 1671.197505 & {$[49][M+1]+$} \\
\hline 3.73766E-07 & 349.1 & 1672.1 & {$[50][M+1]+$} \\
\hline $8.29852 \mathrm{E}-10$ & 364.138416 & 1671.586061 & \\
\hline 3.86441E-07 & \begin{tabular}{|l|}
350.1733297 \\
\end{tabular} & 1672.101843 & {$[50][\mathrm{M}+2]+$} \\
\hline $4.44089 \mathrm{E}-16$ & 264.1 & 1921. & {$[60][\mathrm{M}]+$} \\
\hline 2.81464E-12 & 258 & & \\
\hline 0 & 265.1442719 & 1921.525893 & {$[60][M+1]+$} \\
\hline
\end{tabular}




\begin{tabular}{|c|c|c|c|}
\hline $2.05296 E-11$ & 305.1720731 & 1921.15953 & \\
\hline 0.014651845 & 321.1693713 & 1921.721262 & \\
\hline $4.35318 E-12$ & 231.0999318 & 1721.967116 & {$[62][\mathrm{M}]+$} \\
\hline $5.01209 E-09$ & 272.1290451 & 1722.906013 & {$[63][\mathrm{M}]+$} \\
\hline $1.06581 E-14$ & 232.1092284 & 1721.197485 & {$[62][\mathrm{M}+1]+$} \\
\hline $4.00188 E-10$ & 273.1361768 & 1721.560939 & {$[63][\mathrm{M}+1]+$} \\
\hline $1.15695 E-10$ & 233.1125381 & 1720.572456 & {$[62][\mathrm{M}+2]+$} \\
\hline $2.26861 E-05$ & 548.2089466 & 1091.70815 & {$[64][\mathrm{M}]+$} \\
\hline $2.01323 E-05$ & 549.2187797 & 1091.70815 & {$[64][\mathrm{M}+1]+$} \\
\hline $2.87621 E-08$ & 570.1974478 & 1091.785586 & {$[65][\mathrm{M}]+$} \\
\hline $2.17864 E-06$ & 571.2019639 & 1091.732883 & {$[65][\mathrm{M}+1]+$} \\
\hline $5.10882 E-09$ & 310.182849 & 2000.341207 & {$[66][\mathrm{M}]+$} \\
\hline 0.003071409 & 244.1103332 & 2002.774216 & \\
\hline $2.16364 E-08$ & 311.1882177 & 2000.286668 & {$[66][\mathrm{M}+1]+$} \\
\hline 0.002198696 & 242.1220082 & 2000.622518 & \\
\hline $1.40675 E-05$ & 332.1661945 & 2001.070012 & \\
\hline $1.0508 E-05$ & 351.2154818 & 2000.277004 & \\
\hline $6.80335 E-06$ & 312.1932443 & 2000.277004 & {$[66][\mathrm{M}+2]+$} \\
\hline $3.79461 E-06$ & 231.0699965 & 1088.217064 & {$[109][\mathrm{M}]+$} \\
\hline $2.71372 E-05$ & 272.0966672 & 1088.171893 & {$[110][\mathrm{M}]+$} \\
\hline $3.52599 E-05$ & 232.0741416 & 1088.027702 & {$[109][\mathrm{M}+1]+$} \\
\hline 0.000279277 & 273.1062782 & 1086.845614 & {$[110][\mathrm{M}+1]+$} \\
\hline 0.000196877 & 218.1229754 & 1520.277359 & \\
\hline $3.92608 E-10$ & 473.2207663 & 1522.561706 & {$[111][\mathrm{M}]+$} \\
\hline $4.2705 E-11$ & 490.2468165 & 1521.878499 & \\
\hline 0.007574759 & 474.2271077 & 1522.974235 & {$[111][\mathrm{M}+1]+$} \\
\hline $6.11977 E-12$ & 536.2273197 & 1520.621652 & \\
\hline & & & \\
\hline
\end{tabular}




\section{higher in Carrizo citrange than Cleopatra mandarin non-stressed $p$}

adduct Carrizo citrange Cleopatra mandarin fold change

\begin{tabular}{|c|c|c|c|}
\hline$[\mathrm{M}+\mathrm{H}]+312.13$ & 290184.0208 & 23908.24764 & 12.14 \\
\hline & 85505.08195 & 3865.860407 & \\
\hline & 10638.48459 & 258.6482332 & \\
\hline \multirow[t]{2}{*}[\mathrm{M}+\mathrm{Na}+\mathrm{ACN}]{+353.166} & 12892.57719 & 397.8099814 & \\
\hline & 1916.406354 & 52.3790692 & \\
\hline \multirow[t]{2}{*}[2\mathrm{M}+\mathrm{H}]{+312.14} & 4861.67793 & 11.5790206 & \\
\hline & 1622.005022 & 7.054174825 & \\
\hline \multirow[t]{3}{*}[\mathrm{M}+\mathrm{H}]{+327.16} & 186778.211 & 1969.812091 & 94.82 \\
\hline & 20019.34932 & 104.7335221 & \\
\hline & 1832.439992 & 3.324694453 & \\
\hline \multirow[t]{2}{*}[M+ACN]{+327.16} & 11214.75131 & 7.475435945 & \\
\hline & 1504.509133 & 2.271053048 & \\
\hline \multirow[t]{4}{*}[\mathrm{M}+\mathrm{Na}+\mathrm{ACN}]{+327.16} & 16166.09755 & 77.10016911 & \\
\hline & 2498.772399 & 13.53596688 & \\
\hline & 17945.29399 & 4.726566201 & \\
\hline & 5566.518071 & 4.675706559 & \\
\hline \multirow[t]{2}{*}[\mathrm{M}-\mathrm{C}3\mathrm{H}4]{+299.12} & 94076.36495 & 62780.35866 & 1.50 \\
\hline & 9996.135234 & 7663.635389 & \\
\hline \multirow[t]{2}{*}[M+H]{+299.12} & 53064.05615 & 36420.29187 & 1.46 \\
\hline & 8610.43796 & 5877.710911 & \\
\hline [M-C3H4N2]+ & 308909.793 & 7965.682322 & 38.78 \\
\hline \multirow[t]{7}{*}[\mathrm{M}+\mathrm{H}]{+380.207} & 233584.7679 & 14443.4521 & \\
\hline & 130960.5368 & 2672.148282 & \\
\hline & 47686.67399 & 1134.73395 & \\
\hline & 35576.48538 & 1553.089874 & \\
\hline & 16112.18599 & 176.2863332 & \\
\hline & 11915.49538 & 2.684322767 & \\
\hline & 5179.249081 & 48.89602021 & \\
\hline \multirow[t]{3}{*}[\mathrm{M}+\mathrm{K}]{+380.207} & 4540.259868 & 83.59180512 & \\
\hline & 2800.738759 & 6.595742735 & \\
\hline & 2780.013625 & 7.875899558 & \\
\hline \multirow[t]{3}{*}[\mathrm{M}+\mathrm{Na}]{+380.207} & 2648.982829 & 77.01910739 & \\
\hline & 2626.925459 & 2.637831669 & \\
\hline & 837.1135461 & 3.27224688 & \\
\hline$[\mathrm{M}+\mathrm{H}-\mathrm{H} 2 \mathrm{O}]+325.174$ & 68458.19485 & 14798.45544 & 4.63 \\
\hline$[\mathrm{M}+\mathrm{H}]+325.174$ & 56966.12599 & 9375.724894 & \\
\hline \multirow[t]{4}{*}[\mathrm{M}+\mathrm{Na}]{+325.174} & 31408.942 & 7330.142756 & \\
\hline & 13148.85016 & 2913.035956 & \\
\hline & 10961.55686 & 1502.04594 & \\
\hline & 6810.927018 & 1357.883302 & \\
\hline \multirow[t]{2}{*}[M+K]{+325.174} & 3400.106326 & 348.8370896 & \\
\hline & 554.5114275 & 158.072588 & \\
\hline \multirow[t]{3}{*}[\mathrm{M}+\mathrm{H}]{+263.13} & 148350.7466 & 15.03034001 & 9870.09 \\
\hline & 32549.72879 & 8451.17319 & \\
\hline & 25504.56771 & 460.6893242 & \\
\hline
\end{tabular}




\begin{tabular}{|c|c|c|c|}
\hline$[M+A C N]+263.13$ & 869.7572447 & 18.53779447 & \\
\hline & 283.9420179 & 174.9197311 & \\
\hline$[\mathrm{M}+\mathrm{H}]+230.09$ & 152102.9009 & 54337.27383 & 2.80 \\
\hline \multirow[t]{4}{*}[\mathrm{M}+\mathrm{ACN}]{+230.09} & 28357.59972 & 13964.05822 & \\
\hline & 17890.71071 & 5635.789139 & \\
\hline & 3958.791388 & 1049.540779 & \\
\hline & 1671.251573 & 498.0187971 & \\
\hline \multirow[t]{2}{*}[\mathrm{M}+\mathrm{H}]{+547.204} & 79535.84179 & 39495.1967 & 2.01 \\
\hline & 18995.14586 & 9366.461777 & \\
\hline \multirow{2}{*}[\mathrm{M}+\mathrm{Na}]{+547.204} & 16632.70894 & 8438.976455 & \\
\hline & 3167.260537 & 1517.859274 & \\
\hline \multirow[t]{4}{*}[\mathrm{M}+\mathrm{H}]{+309.176} & 63711.5784 & 37734.76948 & 1.69 \\
\hline & 15289.6609 & 9095.195676 & \\
\hline & 12111.11292 & 7501.631374 & \\
\hline & 10177.35936 & 7445.505253 & \\
\hline \multirow[t]{3}{*}[\mathrm{M}+\mathrm{Na}]{+309.176} & 6401.723536 & 2884.040591 & \\
\hline & 1188.822668 & 560.9396299 & \\
\hline & 806.0839477 & 420.6298443 & \\
\hline$[\mathrm{M}+\mathrm{H}]+$ & 21859.3092 & 10707.45453 & 2.04 \\
\hline \multirow{3}{*}[\mathrm{M}+\mathrm{ACN}]{+} & 13058.07999 & 4381.571537 & \\
\hline & 2473.9932 & 1129.149933 & \\
\hline & 2208.172882 & 894.927201 & \\
\hline$[\mathrm{M}+\mathrm{H}]+217.119$ & 22496.26032 & 6839.958659 & 3.29 \\
\hline$[\mathrm{M}+\mathrm{H}-\mathrm{NH} 3]+489.239$ & 19985.70579 & 118.8699554 & \\
\hline \multirow[t]{3}{*}[\mathrm{M}+\mathrm{H}]{+489.239} & 8424.239977 & 22.96569662 & \\
\hline & 4420.331499 & 2698.315243 & \\
\hline & 668.3688678 & 22.20534603 & \\
\hline
\end{tabular}




\section{lants.}

hydroxycinnamyl alcohol glycoside

1

2

4

5

6

7

8

9

10

11

12

13

14

15

16

17

18

19

20

21

22

23

24

25

26

27

28

29

30

31

32

33

34

35

36

37

38

39

40

41

42

43

44

45

46

47

48

49

50

51

52

53

54

55

56

57

58

59

60 


\section{Supplementary Data 7.}

\section{Mass chromatographic features with area values I}

\begin{tabular}{|c|c|c|c|}
\hline alc & $m z$ & $r t(s)$ & isotopes \\
\hline $9.80 \mathrm{E}-04$ & 282.264433 & 2777.089954 & \\
\hline 3.54E-04 & 283.2855498 & 2776.680982 & {$[5][\mathrm{M}]+$} \\
\hline $2.86 \mathrm{E}-03$ & 323.3094487 & 2777.080931 & [6][M]+ \\
\hline $1.29 \mathrm{E}-04$ & 265.257675 & \begin{tabular}{|l|}
2776.841276 \\
\end{tabular} & [4][M]+ \\
\hline $3.19 \mathrm{E}-03$ & 563.5572439 & 2776.83698 & \\
\hline 8.93E-05 & 247.2474115 & 2776.755472 & \\
\hline $2.00 \mathrm{E}-04$ & 284.2940806 & 2776.606811 & {$[5][M+1]+$} \\
\hline 3.87E-03 & 324.3144327 & 2776.765285 & {$[6][M+1]+$} \\
\hline $1.83 \mathrm{E}-04$ & 266.2625381 & 2776.515146 & {$[4][M+1]+$} \\
\hline $1.50 \mathrm{E}-04$ & 259.0984867 & 1906.000845 & \\
\hline $0.00 \mathrm{E}+00$ & 260.1057441 & 1905.829779 & [7][M]+ \\
\hline 3.45E-11 & 300.1266018 & 1906.666895 & {$[8][\mathrm{M}]+$} \\
\hline $6.94 \mathrm{E}-06$ & 259.4670555 & 1906.071538 & \\
\hline $1.68 \mathrm{E}-09$ & 557.2696479 & 1907 & \\
\hline $2.41 \mathrm{E}-08$ & 517.1931607 & 1907.693864 & \\
\hline $0.00 \mathrm{E}+00$ & 322.1102053 & 1907.80293 & [9][M]+ \\
\hline $0.00 \mathrm{E}+00$ & 261.1046813 & 1907.439723 & {$[7][M+1]+$} \\
\hline $1.19 \mathrm{E}-12$ & 301.1325032 & 1907.187266 & {$[8][M+1]+$} \\
\hline $0.00 \mathrm{E}+00$ & 539.1759875 & 1908.524679 & {$[11][\mathrm{M}]+$} \\
\hline $0.00 \mathrm{E}+00$ & 556.6744066 & 1907.836455 & {$[12][\mathrm{M}]+$} \\
\hline $2.22 \mathrm{E}-16$ & 528.1729001 & 1906. & [10][M]2+ \\
\hline $4.46 \mathrm{E}-10$ & 657.2160183 & 1906.49247 & \\
\hline $5.27 E-11$ & 665.2128359 & 1907.901058 & [13][M]2+ \\
\hline $4.38 \mathrm{E}-10$ & 665.7123527 & 1907.72807 & {$[13][M+1] 2+$} \\
\hline 4.44E-16 & 549.1828804 & 1905.502942 & \\
\hline $2.22 \mathrm{E}-15$ & 528.6734256 & 1906.294882 & {$[10][\mathrm{M}+1] 2+$} \\
\hline $0.00 \mathrm{E}+00$ & 323.1133731 & 1907.78808 & {$[9][M+1]+$} \\
\hline $2.70 \mathrm{E}-10$ & 536.163264 & 1906.592086 & \\
\hline $0.00 \mathrm{E}+00$ & 540.1771036 & 1907.836455 & {$[11][M+1]+$} \\
\hline $2.59 \mathrm{E}-07$ & 544.1540877 & 1907.81778 & \\
\hline 5.57E-14 & 529.1754832 & 1906.773627 & {$[10][M+2] 2+$} \\
\hline $1.62 \mathrm{E}-11$ & 521.1772495 & 1903.482825 & \\
\hline 3.35E-14 & 557.6826402 & 1907.984266 & {$[12][\mathrm{M}+1]+$} \\
\hline $7.66 \mathrm{E}-04$ & 457.1712724 & 1735.914695 & {$[18][\mathrm{M}]+$} \\
\hline $1.98 \mathrm{E}-03$ & 468.156872 & 1736.477701 & \\
\hline $1.68 \mathrm{E}-06$ & 590.1834097 & 1737.923629 & \\
\hline 8.93E-04 & 458.1759674 & 1735.975807 & {$[18][\mathrm{M}+1]+$} \\
\hline $2.05 \mathrm{E}-02$ & 378.1142715 & 1736.60855 & \\
\hline $5.22 \mathrm{E}-12$ & 245.1043824 & 2048.249023 & {$[24][\mathrm{M}+]+$} \\
\hline 2.14E-09 & 286.1458768 & 2048.071294 & {$[25][\mathrm{M}]+$} \\
\hline $0.00 \mathrm{E}+00$ & 246.1214227 & 2048.095801 & {$[24][\mathrm{M}+1]+$} \\
\hline $4.13 E-10$ & 287.1529635 & 2048.095801 & {$[25][M+1]+$} \\
\hline $0.00 \mathrm{E}+00$ & 247.1284897 & 2048.095801 & {$[24][\mathrm{M}+2]+$} \\
\hline $2.88 \mathrm{E}-06$ & 489.2338413 & 2047.643557 & \\
\hline $4.51 \mathrm{E}-11$ & 288.1562985 & 2047.566656 & {$[25][\mathrm{M}+2]+$} \\
\hline
\end{tabular}




\begin{tabular}{|c|c|c|c|}
\hline $4.44 \mathrm{E}-16$ & 308.169005 & 1772.875798 & {$[29][M]+$} \\
\hline $5.55 E-15$ & 309.1736901 & 1772.93815 & {$[29][M+1]+$} \\
\hline $1.39 \mathrm{E}-09$ & \begin{tabular}{|l|}
193.1031453 \\
\end{tabular} & 1774.016844 & \\
\hline $4.64 \mathrm{E}-05$ & 231.0965088 & 1561.800315 & {$[31][\mathrm{M}]+$} \\
\hline $1.04 \mathrm{E}-03$ & 272.1302097 & 1561.537083 & {$[32][M]+$} \\
\hline $2.16 \mathrm{E}-06$ & \begin{tabular}{|l|}
216.0701393 \\
\end{tabular} & 1561.878427 & {$[30][\mathrm{M}]+$} \\
\hline $2.24 \mathrm{E}-05$ & \begin{tabular}{|l|}
232.1077652 \\
\end{tabular} & 1561.878427 & {$[31][M+1]+$} \\
\hline $3.32 E-04$ & 273.1367925 & 1561.718629 & {$[32][M+1]+$} \\
\hline $4.16 \mathrm{E}-06$ & \begin{tabular}{|l|}
217.0769333 \\
\end{tabular} & 1561.752874 & {$[30][\mathrm{M}+1]+$} \\
\hline $1.15 \mathrm{E}-03$ & 175.0460425 & 1561.439806 & \\
\hline $2.05 \mathrm{E}-07$ & \begin{tabular}{|l|}
224.1019082 \\
\end{tabular} & 1448.156258 & {$[33][\mathrm{M}]+$} \\
\hline $2.98 \mathrm{E}-07$ & 225.112756 & 1447.66845 & {$[33][M+1]+$} \\
\hline $6.27 E-07$ & \begin{tabular}{|l|}
265.1386393 \\
\end{tabular} & 1448.635079 & \\
\hline 5.44E-06 & 226.1191194 & 1447.66845 & {$[33][M+2]+$} \\
\hline 3.27E-04 & 105.0434649 & 1447 & \\
\hline $5.74 \mathrm{E}-09$ & 9735 & 1958 & {$[34][\mathrm{M}]+$} \\
\hline $1.02 \mathrm{E}-05$ & 286.1406358 & 1958.188211 & {$[35][\mathrm{M}]+$} \\
\hline $2.12 \mathrm{E}-06$ & \begin{tabular}{|l|}
230.0895316 \\
\end{tabular} & 32922 & \\
\hline $1.36 \mathrm{E}-08$ & 31605 & 1958. & {$[34][M+1]+$} \\
\hline $4.68 \mathrm{E}-06$ & 287.1504612 & 1957.820256 & {$[35][M+1]+$} \\
\hline $1.40 \mathrm{E}-08$ & 247.1265824 & 195 & {$[34][M+2]+$} \\
\hline 4.59E-07 & 189.0 & 195 & \\
\hline $3.73 E-14$ & 245.0808304 & 1512.70364 & {$[36][\mathrm{M}]+$} \\
\hline $2.16 \mathrm{E}-11$ & 246.0888173 & 1513.063872 & {$[36][M+1]+$} \\
\hline $9.89 \mathrm{E}-08$ & 27624 & 364 & \\
\hline $2.14 \mathrm{E}-12$ & 247. & 151 & {$[36][M+2]+$} \\
\hline $6.26 \mathrm{E}-11$ & 308.1023736 & 1513 & \\
\hline $6.66 \mathrm{E}-16$ & 227.1 & 1817 & \\
\hline $1.68 \mathrm{E}-06$ & 195. & 988 & \\
\hline $0.00 E+00$ & 249.1 & 1817. & \\
\hline $2.13 E-14$ & 306. & 189 & {$[43][\mathrm{M}]+$} \\
\hline $1.44 \mathrm{E}-08$ & 281. & & \\
\hline $1.03 \mathrm{E}-12$ & 265. & 189 & \\
\hline $1.02 \mathrm{E}-14$ & 307.1 & 1897. & {$[43][\mathrm{M}+1]+$} \\
\hline $1.65 \mathrm{E}-13$ & 533.1 & 1897. & \\
\hline $5.24 \mathrm{E}-14$ & 261.1 & 130 & {$[\mathrm{M}]+$} \\
\hline 1.17E-08 & \begin{tabular}{|l|}
262.1149881 \\
\end{tabular} & 1305.459417 & {$[\mathrm{M}+1]+$} \\
\hline $2.96 \mathrm{E}-09$ & 302.1425513 & 1306.613596 & {$[51][\mathrm{M}]+$} \\
\hline $1.33 \mathrm{E}-02$ & \begin{tabular}{|l|}
263.1071071 \\
\end{tabular} & 1304.575495 & {$[\mathrm{M}+2]+$} \\
\hline $2.48 \mathrm{E}-09$ & 303.1466126 & 1307.525899 & {$[51][M+1]+$} \\
\hline $7.51 E-03$ & 225.1453602 & 1686.865482 & {$[52][M]+$} \\
\hline $1.71 \mathrm{E}-05$ & \begin{tabular}{|l|}
266.1787386 \\
\end{tabular} & 1686.931744 & [53][M]+ \\
\hline $4.30 \mathrm{E}-04$ & 226.1562533 & 1686.67035 & {$[52][M+1]+$} \\
\hline $1.36 \mathrm{E}-08$ & 210.1174399 & 1686.984823 & \\
\hline $8.20 \mathrm{E}-08$ & 234.1531421 & 1687.014686 & \\
\hline $1.09 \mathrm{E}-06$ & 267.1832447 & 1686.69904 & {$[53][M+1]+$} \\
\hline 3.54E-05 & \begin{tabular}{|l|}
227.1579162 \\
\end{tabular} & 1686.539025 & {$[52][M+2]+$} \\
\hline $2.14 \mathrm{E}-08$ & 211.1293976 & 1686.822934 & \\
\hline $4.82 \mathrm{E}-04$ & 235.1475353 & 1685.340052 & \\
\hline $4.79 \mathrm{E}-08$ & 223.0624263 & 1021.801644 & [55][M]+ \\
\hline
\end{tabular}




\begin{tabular}{|c|c|c|c|}
\hline $1.59 \mathrm{E}-08$ & 224.0677965 & 1021.715512 & {$[55][M+1]+$} \\
\hline $3.56 \mathrm{E}-07$ & 225.0765657 & 1022.112998 & {$[55][M+2]+$} \\
\hline $1.46 \mathrm{E}-08$ & 309.122711 & 1020.529389 & \\
\hline $1.85 \mathrm{E}-03$ & 245.0799603 & 1303.248494 & {$[56][\mathrm{M}]+$} \\
\hline $8.96 \mathrm{E}-08$ & 267.0672697 & 1303.850353 & {$[57][\mathrm{M}]+$} \\
\hline $1.56 \mathrm{E}-04$ & 246.0888778 & 1303.026233 & {$[56][M+1]+$} \\
\hline 5.75E-06 & 308.0946227 & 1303.553662 & {$[59][\mathrm{M}]+$} \\
\hline $1.39 \mathrm{E}-08$ & 268.0744185 & 1303.745658 & {$[57][\mathrm{M}+1]+$} \\
\hline $1.72 \mathrm{E}-05$ & 309.0974046 & 1302.964643 & {$[59][M+1]+$} \\
\hline $9.39 E-06$ & 237.0799463 & 1151.07355 & {$[61][M]+$} \\
\hline $5.53 \mathrm{E}-13$ & 293.1064854 & 1152.159883 & \\
\hline $1.98 \mathrm{E}-05$ & 238.0847699 & 1150.934575 & {$[61][M+1]+$} \\
\hline $1.30 \mathrm{E}-03$ & 278.1127998 & 1153.116238 & \\
\hline $2.54 \mathrm{E}-04$ & 14065 & 1647 & \\
\hline $2.39 \mathrm{E}-11$ & 329.1384115 & 1832.177331 & {$[67][\mathrm{M}]+$} \\
\hline $1.20 \mathrm{E}-04$ & 347.1526412 & 1831.370275 & {$[68][\mathrm{M}]+$} \\
\hline 1.47E-05 & 410.1615116 & 1830.6 & प]+ \\
\hline $5.25 \mathrm{E}-07$ & 715.2765116 & 1831.031487 & [74][M]+ \\
\hline 2.51E-12 & 330.1459459 & 1832.20026 & {$[67][M+1]+$} \\
\hline 2.79E-07 & 369.1356852 & 1830.359678 & M]+ \\
\hline 9.77E-07 & 385 & 1831 & {$[72][\mathrm{M}]+$} \\
\hline 8.07E-09 & 716.2834353 & 1831.006556 & {$[74][M+1]+$} \\
\hline $6.96 \mathrm{E}-05$ & 348.1569645 & 1831.330608 & {$[68][M+1]+$} \\
\hline 4.05E-06 & 411.1 & 1831.079565 & {$[73][M+1]+$} \\
\hline $5.92 \mathrm{E}-08$ & 379.1810379 & 1831.693027 & {$[71][\mathrm{M}]+$} \\
\hline $2.25 \mathrm{E}-05$ & 22671 & 183 & \\
\hline $2.44 \mathrm{E}-08$ & 370.1410139 & 1830.133763 & {$[70][M+1]+$} \\
\hline 2.09E-09 & 331.1504048 & 1831.676713 & {$[67][M+2]+$} \\
\hline 8.10E-06 & 386.115981 & 1830.979651 & {$[72][M+1]+$} \\
\hline 1.77E-05 & 380.185505 & 1831.97623 & {$[71][M+1]+$} \\
\hline $9.62 \mathrm{E}-06$ & 412.1732428 & 1829.935667 & {$[73][M+2]+$} \\
\hline 1.71E-09 & 224.1092715 & 1794.545851 & {$[75][\mathrm{M}]+$} \\
\hline 1.03E-09 & 225.1217874 & 1794.647183 & {$[75][M+1]+$} \\
\hline $1.35 \mathrm{E}-07$ & 265.1391286 & 1794.7 & \\
\hline 1.17E-03 & 355.1038989 & 663.4085103 & {$[78][\mathrm{M}]+$} \\
\hline $1.37 \mathrm{E}-03$ & 356.1109769 & 663.1219429 & {$[78][M+1]+$} \\
\hline 2.73E-03 & 411.218581 & 1697. & \\
\hline $3.22 \mathrm{E}-04$ & 393.2100445 & 1697.5 & \\
\hline $1.62 \mathrm{E}-02$ & 437.2036237 & 1697.405528 & \\
\hline $4.80 \mathrm{E}-04$ & 297.2931433 & 2710.649083 & {$[86][\mathrm{M}]+$} \\
\hline $3.44 \mathrm{E}-04$ & 298.2996515 & 2710.736262 & {$[86][M+1]+$} \\
\hline $2.73 \mathrm{E}-03$ & 256.270041 & 2710.641451 & [85][M]+ \\
\hline 4.16E-03 & 257.2741232 & 2710.647738 & {$[85][M+1]+$} \\
\hline $1.76 \mathrm{E}-08$ & 515.228536 & 1220.651216 & [91][M]+ \\
\hline 2.83E-09 & 516.2347258 & 1220.293959 & {$[91][M+1]+$} \\
\hline $3.14 \mathrm{E}-10$ & 455.2118822 & 1221.622279 & {$[90][\mathrm{M}]+$} \\
\hline $3.60 \mathrm{E}-07$ & 471.2416474 & 1219.743618 & \\
\hline $1.78 \mathrm{E}-08$ & 517.2372739 & 1220.474615 & {$[91][M+2]+$} \\
\hline 5.84E-09 & 456.2134189 & 1220.610322 & {$[90][M+1]+$} \\
\hline
\end{tabular}




\section{higher in Cleopatra mandarin than Carrizo citrange non-stressed p}

\begin{tabular}{|c|c|c|c|}
\hline adduct & Carrizo citrange & Cleopatra mandarin & fold change \\
\hline \multirow{3}{*}[\mathrm{M}+\mathrm{H}]{+281.264} & 374504.3098 & 482457.8463 & 1.28825713 \\
\hline & 77873.62817 & 122034.0111 & \\
\hline & 29616.5264 & 53107.76225 & \\
\hline$[\mathrm{M}+\mathrm{H}-\mathrm{NH} 3]+281.264$ & 15865.28319 & 28801.41417 & \\
\hline \multirow[t]{5}{*}[2\mathrm{M}+\mathrm{H}]{+281.264} & 8915.712117 & 19066.50631 & \\
\hline & 5601.698334 & 11119.59738 & \\
\hline & 6728.67628 & 10499.22138 & \\
\hline & 5338.318385 & 9488.495519 & \\
\hline & 2339.569332 & 4680.089996 & \\
\hline \multirow[t]{2}{*}[\mathrm{M}+\mathrm{H}]{+258.098} & 57917.30935 & 274585.8598 & 4.74099821 \\
\hline & 11798.18674 & 199598.8449 & \\
\hline \multirow[t]{3}{*}[M+ACN]{+258.098} & 2873.04505 & 115819.6709 & \\
\hline & 0.027302946 & 72582.64021 & \\
\hline & 485.3981055 & 25763.45665 & \\
\hline$[2 \mathrm{M}+\mathrm{H}]+258.098$ & 44.60420569 & 23479.25944 & \\
\hline \multirow[t]{3}{*}[\mathrm{M}+\mathrm{Na}+\mathrm{ACN}]{+258.098} & 68.22574465 & 19321.76623 & \\
\hline & 889.0319223 & 17617.86652 & \\
\hline & 212.8192158 & 17463.64988 & \\
\hline \multirow[t]{13}{*}[2\mathrm{M}+\mathrm{Na}]{+258.098} & 19.06911034 & 8018.889042 & \\
\hline & 33.29466123 & 6373.399498 & \\
\hline & 21.17773324 & 6078.900338 & \\
\hline & 4.874408221 & 6075.009248 & \\
\hline & 0.933524186 & 5362.077042 & \\
\hline & 0.172876234 & 4133.540336 & \\
\hline & 6.299312062 & 3968.442212 & \\
\hline & 3.996801306 & 3834.110792 & \\
\hline & 6.201457766 & 2375.396246 & \\
\hline & 9.748552816 & 1875.380666 & \\
\hline & 6.151756514 & 1824.203565 & \\
\hline & 3.156869095 & 1737.438006 & \\
\hline & 8.849406736 & 1526.278104 & \\
\hline \multirow[t]{3}{*}[\mathrm{M}+\mathrm{H}-\mathrm{CO}]{+548.173} & 34.22624497 & 1470.072602 & \\
\hline & 5.443295413 & 937.7502821 & \\
\hline & 14273.14579 & 33483.91573 & 2.34593805 \\
\hline \multirow[t]{4}{*}[\mathrm{M}+\mathrm{Na}]{+445.172} & 7505.1339 & 15325.31055 & \\
\hline & 4477.086871 & 13383.06821 & \\
\hline & 2610.80365 & 6902.739174 & \\
\hline & 694.3880712 & 1182.124367 & \\
\hline$[\mathrm{M}+\mathrm{H}]+244.101$ & 232161.121 & 499186.0885 & 2.15017091 \\
\hline \multirow[t]{4}{*}[M+ACN]{+244.101} & 38308.70834 & 145667.3419 & \\
\hline & 37179.07425 & 105417.163 & \\
\hline & 6098.451998 & 22972.29535 & \\
\hline & 3923.333215 & 10555.89938 & \\
\hline \multirow[t]{2}{*}[2\mathrm{M}+\mathrm{H}]{+244.101} & 112.2384382 & 1896.704333 & \\
\hline & 286.1864438 & 1880.690709 & \\
\hline
\end{tabular}




\begin{tabular}{|c|c|c|c|}
\hline & 3893.079251 & 12605.25648 & 3.2378628 \\
\hline & 621.6363947 & 2279.731898 & \\
\hline & 62.02274217 & 1027.810449 & \\
\hline$[\mathrm{M}+\mathrm{H}]+230.088$ & 184626.7995 & 279221.6519 & 1.5123571 \\
\hline$[M+A C N]+230.088$ & 43411.02213 & 77536.14672 & \\
\hline \multirow[t]{4}{*}[\mathrm{M}+\mathrm{H}-\mathrm{CH}3]{+230.088} & 22630.67383 & 44363.04623 & \\
\hline & 24753.83629 & 41861.54418 & \\
\hline & 6735.611467 & 12443.21176 & \\
\hline & 2755.692972 & 5660.699224 & \\
\hline$[\mathrm{M}-\mathrm{C} 3 \mathrm{H} 6 \mathrm{~N}]+230.088$ & 339.6423767 & 980.9973961 & \\
\hline \multirow[t]{2}{*}[\mathrm{M}+\mathrm{H}]{+223.095} & 163035.4046 & 318905.1202 & 1.95604826 \\
\hline & 25076.28813 & 57675.39669 & \\
\hline \multirow[t]{2}{*}[M+ACN]{+223.095} & 2422.514681 & 7402.354795 & \\
\hline & 2521.885514 & 5230.867874 & \\
\hline$[\mathrm{M}-\mathrm{C} 3 \mathrm{H} 7 \mathrm{N2O3}]+223.095$ & 652.1120904 & 1526.848592 & \\
\hline$[M+H]+244.108$ & 41539.03396 & 190119.2431 & 4.57688167 \\
\hline$[M+A C N]+244.108$ & 9102.527179 & 39388.90736 & \\
\hline \multirow[t]{5}{*}[\mathrm{M}+\mathrm{H}-\mathrm{CH}3]{+244.108} & 14124.26869 & 33732.67456 & \\
\hline & 5721.742955 & 28858.96445 & \\
\hline & 1096.450379 & 6298.880204 & \\
\hline & 383.4765063 & 2782.297786 & \\
\hline & 176.7644056 & 2001.287187 & \\
\hline \multirow[t]{2}{*}[M+H]{+244.08} & 59778.75991 & 200427.9848 & 3.35282942 \\
\hline & 9096.319033 & 28288.90244 & \\
\hline \multirow[t]{2}{*}[M+ACN]{+244.08} & 4849.203991 & 21692.62277 & \\
\hline & 699.1236096 & 3199.740179 & \\
\hline$[\mathrm{M}+\mathrm{Na}+\mathrm{ACN}]+244.08$ & 230.6469073 & 1045.247284 & \\
\hline \multirow[t]{2}{*}[\mathrm{M}+\mathrm{H}]{+226.16} & 32390.83067 & 56622.89799 & 1.74811503 \\
\hline & 7059.076979 & 11439.26226 & \\
\hline$[\mathrm{M}+\mathrm{Na}]+226.16$ & 1279.924137 & 4981.612981 & \\
\hline$[\mathrm{M}+\mathrm{Na}]+283.123$ & 7482.58695 & 14726.1417 & 1.96805487 \\
\hline$[M+2 K] 2+484.197$ & 1393.361651 & 2290.52497 & \\
\hline \multirow[t]{3}{*}[\mathrm{M}+2\mathrm{Na}]{$2+484.197$} & 756.6920101 & 1821.365313 & \\
\hline & 631.6201329 & 1749.406011 & \\
\hline & 175.9438447 & 1973.493261 & \\
\hline \multirow[t]{2}{*}[\mathrm{M}+\mathrm{H}]{+260.10} & 20790.58814 & 153706.3618 & 7.39307425 \\
\hline & 18301.8863 & 32801.6492 & \\
\hline \multirow[t]{3}{*}[M+ACN]{+260.10} & 1527.239529 & 15504.14404 & \\
\hline & 6384.564971 & 7878.714149 & \\
\hline & 96.78046349 & 2268.464573 & \\
\hline$[\mathrm{M}+\mathrm{H}]+224.137$ & 176816.9186 & 234304.6096 & 1.32512551 \\
\hline \multirow[t]{2}{*}[M+ACN]{+224.137} & 33251.15317 & 47775.70615 & \\
\hline & 23320.91151 & 33010.40826 & \\
\hline \multirow[t]{4}{*}[\mathrm{M}+\mathrm{H}-\mathrm{CH}3]{+224.137} & 7320.716647 & 14084.01083 & \\
\hline & 3894.798965 & 7390.104951 & \\
\hline & 4581.939603 & 6954.373117 & \\
\hline & 2200.570187 & 3645.525415 & \\
\hline \multirow[t]{3}{*}[\mathrm{M}+\mathrm{H}-\mathrm{CH}2]{+224.137} & 1449.394416 & 3156.797217 & \\
\hline & 743.77066 & 1318.805928 & \\
\hline & 16306.27451 & 104907.6073 & 6.43357299 \\
\hline
\end{tabular}




\begin{tabular}{|c|c|c|c|}
\hline & 1675.702212 & 11832.07435 & \\
\hline & 215.1901782 & 1567.48386 & \\
\hline & 77.7463572 & 1494.464951 & \\
\hline$[\mathrm{M}+\mathrm{H}]+244.074$ & 108502.2651 & 133896.207 & 1.23404066 \\
\hline \multirow[t]{2}{*}[\mathrm{M}+\mathrm{Na}]{+244.074} & 6794.368997 & 22029.22622 & \\
\hline & 14407.56955 & 18855.60679 & \\
\hline \multirow[t]{3}{*}[\mathrm{M}+\mathrm{Na}+\mathrm{ACN}]{+244.074} & 2035.634002 & 9226.318689 & \\
\hline & 535.0651045 & 2632.098824 & \\
\hline & 146.3806251 & 938.5281094 & \\
\hline \multirow[t]{3}{*}[\mathrm{M}+\mathrm{H}]{+236.08} & 5666.360476 & 68674.50128 & 12.1196845 \\
\hline & 143.8813739 & 9322.240125 & \\
\hline & 448.7287595 & 7848.110475 & \\
\hline$[M+A C N]+236.08$ & 2066.649958 & 6232.656559 & \\
\hline$[\mathrm{M}+\mathrm{Na}+\mathrm{ACN}]+236.08$ & 88.62928488 & 3640.929051 & \\
\hline$[\mathrm{M}+\mathrm{H}-\mathrm{H} 2 \mathrm{O}]+346.146$ & 72529.72303 & 134031.4212 & 1.84795165 \\
\hline$[\mathrm{M}+\mathrm{H}]+346.146$ & 36870.98285 & 51546.92268 & \\
\hline$[\mathrm{M}+\mathrm{Na}+\mathrm{ACN}]+346.146$ & 23239.00407 & 44426.37211 & \\
\hline \multirow[t]{2}{*}[2\mathrm{M}+\mathrm{Na}]{+346.146} & 10054.19005 & 31250.47302 & \\
\hline & 12225.37175 & 22672.75677 & \\
\hline$[\mathrm{M}+\mathrm{Na}]+346.146$ & 10394.07255 & 18345.70189 & \\
\hline \multirow[t]{5}{*}[M+K]{+346.146} & 7554.754381 & 13212.23134 & \\
\hline & 2670.380729 & 10230.92482 & \\
\hline & 5851.49438 & 8734.568673 & \\
\hline & 4283.767177 & 8472.937837 & \\
\hline & 4497.051155 & 8376.88151 & \\
\hline \multirow[t]{6}{*}[\mathrm{M}+\mathrm{H}]{+387.173} & 2734.40225 & 4383.072678 & \\
\hline & 1246.536735 & 2510.714754 & \\
\hline & 1125.032599 & 2498.138286 & \\
\hline & 909.2433118 & 1577.525311 & \\
\hline & 504.0203151 & 969.677241 & \\
\hline & 333.9611173 & 662.8653118 & \\
\hline \multirow[t]{2}{*}[\mathrm{M}+\mathrm{H}]{+223.10} & 31869.29641 & 112426.7645 & 3.52774542 \\
\hline & 6129.13081 & 19419.09349 & \\
\hline \multirow[t]{3}{*}[M+ACN]{+223.10} & 1856.446515 & 9151.218936 & \\
\hline & 22248.34503 & 33444.45315 & 1.5032333 \\
\hline & 2717.727976 & 4135.941742 & \\
\hline$[\mathrm{M}-\mathrm{CO} 2]+454.206$ & 2760.846963 & 4586.649889 & 1.66131986 \\
\hline$[\mathrm{M}-2 \times \mathrm{xH} 2 \mathrm{O}]+454.206$ & 1071.266604 & 1959.535232 & \\
\hline$[\mathrm{M}-\mathrm{H} 20]+454.206$ & 961.5262687 & 1449.809324 & \\
\hline \multirow[t]{2}{*}[M+ACN]{+255.27} & 46460.92437 & 84232.9917 & 1.8129857 \\
\hline & 7832.215808 & 14528.45626 & \\
\hline \multirow[t]{2}{*}[\mathrm{M}+\mathrm{H}]{+255.27} & 3442.228957 & 6469.734062 & \\
\hline & 250.4109619 & 673.855499 & \\
\hline \multirow[t]{2}{*}[\mathrm{M}+\mathrm{H}]{+514.222} & 25233.78416 & 64843.65124 & 2.5697157 \\
\hline & 5678.017965 & 15924.53301 & \\
\hline$[\mathrm{M}-\mathrm{CH} 4]+470.234$ & 2410.606859 & 7187.401679 & \\
\hline \multirow[t]{3}{*}[\mathrm{M}-\mathrm{CO}2]{+514.222} & 1277.036429 & 3666.003794 & \\
\hline & 438.8613518 & 2073.046038 & \\
\hline & 275.3852543 & 1251.59415 & \\
\hline
\end{tabular}




\section{lants.}

1

2

4

5

6

11

12

13

14

15

16

17

18

19

20

21

22

23

24

25

26

27

28

29

30

31

32

33

34

35

36

37

38

39

40

41

42

43

44

45

46

47

48

49

50

51

52

53

54

55

56

57

58

59

60 


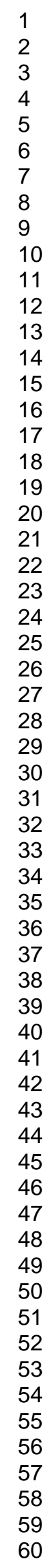


